\begin{tabular}{|c|c|c|c|c|}
\hline $\begin{array}{c}\text { REVISTA ENTORNO } \\
\text { GEOGRÁFICO }\end{array}$ & $\begin{array}{c}\text { Julio/ } \\
\text { Diciembre } \\
2019\end{array}$ & $\mathrm{~N}^{\circ} 18$ & pp. $46-78$ & $\begin{array}{c}\text { ISSN (en línea): 2382-3518/ ISSN } \\
\text { impreso: 1692-0074 }\end{array}$ \\
\hline
\end{tabular}

DOI: 10.25100/eg.v0i18.8626 (c)

Espacios y Territorios

\title{
Identificación de áreas óptimas para la localización de un relleno sanitario en las subregiones norte y oriente del Valle del Cauca
}

\section{Identification of optimal areas for the location of a sanitary landfill in the northern and eastern subregions of Valle del Cauca}

\author{
Iván Andrés Belalcázar Urbano \\ Geógrafo. Departamento de Geografía, Universidad del Valle. Santiago de Cali, Colombia \\ ORCID: 0000-0003-1230-9323 \\ Correo electrónico: belalcazar.ivan@correounivalle.edu.co
}

Para citar este artículo: Belalcázar Urbano, I. (2019). Identificación de áreas óptimas para la localización de un relleno sanitario en las subregiones norte y oriente del Valle del Cauca. Entorno Geográfico, (18). DOI: 10.25100/eg.v0i18. 8626

Resumen: Este estudio busca identificar áreas óptimas en las subregiones Norte y Oriente del Valle del Cauca donde sea posible localizar un relleno sanitario, mediante una metodología que evite al máximo posible los impactos que este tipo de equipamientos ocasiona al medio.

Los municipios de las Subregiones Norte y Oriente del Valle depositan aproximadamente 173,24 ${ }^{1}$ toneladas de residuos sólidos al día. Por la cantidad de residuos sólidos que generan y por no tener un equipamiento donde depositar los desechos de una forma controlada, los municipios del área de estudio deben buscar opciones para llevar a cabo la disposición final en rellenos fuera del departamento o rellenos que se localizan a distancias considerables.

\footnotetext{
${ }^{1}$ Datos del estudio "Disposición Final de Residuos Sólidos Informe Nacional" realizado por la Superintendencia de Servicios Públicos
}

En este orden de ideas, se hace necesario identificar la localización óptima de un relleno subregional que cumpla con los requerimientos de la normatividad actual y que garantice el menor impacto social, económico y ambiental en los municipios involucrados. El presente estudio contribuye a identificar dicha localización, apoyándose en el uso de las tecnologías de información, la revisión de literatura, los principios del desarrollo sostenible y el uso de información espacial detallada.

Palabras clave: Localización, Relleno Sanitario, MCAS-S, Residuos Sólidos urbanos, Áreas óptimas.

Domiciliarios y el Departamento Nacional de Planeación en el 2015. 


\begin{abstract}
This study seeks to identify optimal areas in the northern and eastern subregions of the Valle del Cauca where it is possible to locate a sanitary landfill, using a methodology that avoids as much as possible the impacts that this type of equipment causes to the environment.
\end{abstract}

The municipalities of the North and East Valley Subregions deposit approximately $173.24^{2}$ tons of solid waste per day. For the amount of solid waste they generate and for not having a equipment where to deposit the waste in a controlled manner, the municipalities of the study area should look for options to carry out the final disposal in

Recibido: 29 de mayo de 2019

\section{INTRODUCCIÓN}

$\mathrm{L}_{\mathrm{a}}$

producción de residuos sólidos en

las áreas urbanas, se ha convertido en una de las principales problemáticas a resolver por parte de las autoridades municipales y ambientales del orden territorial. El crecimiento de la población, el consumismo acelerado y la mala calidad de los productos que son fabricados, ayudan a que la generación de residuos sólidos urbanos vaya en aumento. Como propuesta a dicha problemática, se han tratado de implementar diferentes tecnologías que permitan llevar a cabo la disposición final de los residuos, entre esas

\footnotetext{
2 Data from the study "Final Disposal of Solid Waste Nacional Report" conducted by Superintendencia de Servicios Públicos
}

landfills outside the department or landfills that are located at considerable distances.

In this order of ideas, it is necessary to identify the optimal location of a subregional landfill that meets the requirements of current regulations and that guarantees the least social, economic and environmental impact in the municipalities involved. The present study contributes to identify this location, based on the use of information technologies, literature review, principles of sustainable development and the use of detailed spatial information.

Keywords: Location, Landfill, MCAS-S, Urban Solid Waste, Optimal Areas.

Aceptado: 1 de octubre de 2019

tecnologías se encuentra el relleno sanitario.

El relleno sanitario es la tecnología más utilizada en el mundo por los bajos costos, en comparación con otras tecnologías como la pirólisis o incineración, sin embargo, localizar un relleno sanitario resulta bastante complejo si se tiene en cuenta, en primera medida el rechazo de la población, y en segunda medida, los impactos ocasionados al ambiente por los productos contaminantes que resultan de procesos al interior del relleno, si este no es operado de forma correcta.

En vista de que llevar a cabo la localización de un relleno sanitario es tan

Domiciliarios and the Departamento Nacional de Planeación in 2015. 
complejo, este estudio propone desarrollar una metodología donde se tiene en cuenta las características físicas y sociales de la zona de estudio, la normativa colombiana, el enfoque del desarrollo sostenible y los antecedentes de investigación sobre la temática, tratando siempre que el estudio se acerque a la realidad del territorio.

Las características mencionadas fueron integradas utilizando como estrategia la Evaluación Multicriterio (EMC) la cual está incorporada en el aplicativo Análisis

\section{ESPECIFICACIONES DEL ÁREA DE ESTUDIO}

La zona de estudio corresponde a las subregiones Norte y Oriente del Valle del Cauca que limitan al occidente con el departamento de Chocó, al norte con el departamento de Risaralda y al oriente con los departamentos de Quindío y Tolima, mientras que al sur limitan con la subregión centro del Valle del Cauca. El área de estudio está conformada por dieciocho municipios: Alcalá, Ansermanuevo, Argelia, Bolívar, Caicedonia, Cartago, El Águila, El Cairo, El Dovio, La Unión, La Victoria, Obando, Roldanillo, Sevilla, Toro, Ulloa, Versalles y Zarzal. En total, cuentan con una extensión aproximada de $5.100 \mathrm{~km}^{2}$, la subregión Norte tiene aproximadamente $4.300 \mathrm{~km}^{2}$, mientras la subregión Oriente posee alrededor de $800 \mathrm{~km}^{2}$.

Las Subregiones Norte y Oriente del departamento se encuentran rodeadas por las cordilleras Occidental y Central, en el
Multicriterio de Capas para el Soporte de Decisión Espacial (MCAS-S) y sus herramientas como el método de Proceso de Análisis Jerárquico (AHP). Por medio de este se procesaron los datos obtenidos de fuentes locales y nacionales. Como resultado, se obtuvo dos posibles áreas localizadas en los municipios de Toro y Obando. Dichas áreas fueron objeto de análisis y discusión derivando en las recomendaciones presentadas al final del estudio.

centro de ambas se localiza el valle geográfico del río Cauca. La zona de estudio se caracteriza por tener, en su mayoría, un paisaje montañoso. Físicamente, el área analizada presenta diferentes tipos de pendiente, sin embargo, por la influencia de las cordilleras, predomina el relieve montañoso con pendientes superiores al 25\%. En la parte plana, denominada comúnmente valle geográfico del río Cauca, predominan las pendientes que van del 0 al 3\%.

El área de estudio posee una población cercana a los 4.708.262 habitantes según proyecciones del DANE para el año 2017, siendo Cartago, Sevilla y Zarzal los municipios con la mayor cantidad de población. En cuanto a la actividad económica, se destacan Cartago y Zarzal como nodos importantes por sus dinámicas comerciales. En los municipios donde predomina el paisaje de montaña se desarrollan diferentes tipos de cultivos, en los que se destacan el Café y el eucalipto, ya en la parte plana de la subregión norte se repite, al igual que en el resto de la parte 
plana del departamento del Valle del Cauca, el monocultivo de caña de azúcar como actividad económica principal.

\section{REFERENCIAS TEÓRICAS}

La presente investigación tiene como bases teóricas los principios o dimensiones del desarrollo sostenible y la teoría de la

\section{Desarrollo sostenible}

El desarrollo sostenible, como primera base teórica del estudio, busca preservar los recursos naturales para que las generaciones futuras también satisfagan sus necesidades. Según Rodríguez (1994), citando a Hunter (1994), "El desarrollo sostenible reconoce la responsabilidad de cada generación de ser justa con la siguiente generación, mediante la entrega de una herencia de riqueza que no puede ser menor que la que ellos mismos han recibido [...]" (p. 16)

Para evitar que las generaciones futuras presencien una catástrofe medioambiental que no tenga reversa, se ha propuesta que el Desarrollo Sostenible se mire desde tres dimensiones, que interceptadas contribuyan al objetivo del mismo. Las dimensiones económica, social y medioambiental, bajo el lema de viabilidad en el desarrollo económico, equidad y preservación ambiental, son la base y sustento del discurso del desarrollo sostenible.

Dimensión económica: El desarrollo económico no es posible si no se tiene en cuenta sus impactos sobre la sociedad y
Localización Asignación, así mismo, en este apartado se habla sobre la Evaluación Multicriterio (EMC) como herramienta fundamental para llevar a cabo un proceso de localización de un equipamiento.

sobre el medio ambiente, para ello, se debe trabajar de la mano con los servicios que ofrece la naturaleza, manteniendo un equilibrio. Según Artaraz (2002), citando a la Comisión de las Comunidades Europeas (1992), el crecimiento económico es insostenible "si no se tienen en cuenta las consideraciones medioambientales, no sólo como un factor restrictivo, sino como un incentivo para aumentar la eficacia y la competitividad, sobre todo en el mercado mundial"(p.1),

Dimensión social: La dimensión social del desarrollo sostenible se basa en la equidad, la cual se divide en tres tipos: la primera, es la equidad generacional que busca que las futuras generaciones, al igual que la actual, pueda satisfacer las necesidades de su momento, respetando y valorando los servicios que son ofrecidos por lanaturaleza. El segundo tipo de equidad intergeneracional considera la participación de los grupos de poblaciones menos favorecidos o vulnerados, en los asuntos concernientes al desarrollo económico, a la afectación medioambiental y afectación social. La tercera es la equidad entre los países que supone un mayor respeto de los países 
“desarrollados" hacia los países que están en vía de desarrollo.

Dimensión Medioambiental: El concepto de Desarrollo Sostenible surge como consecuencia del agotamiento de los servicios que la naturaleza ofrece a la sociedad. En la dimensión medioambiental se busca que el desarrollo económico no ponga en riesgo el equilibrio natural, ya que, desde el discurso, se entendió que el deterioro del medioambiente conlleva al colapso y fin de la población mundial.

\section{Gestión integral de residuos sólidos}

Dentro de la normativa colombiana, el Decreto 1713 (Minambiente, 2002), define a la Gestión Integral De Residuos Sólidos (GIRS) como "El conjunto de operaciones y disposiciones encaminadas a dar a los residuos producidos el destino más adecuado desde el punto de vista ambiental, de acuerdo con sus características, volumen, procedencia, costos, tratamiento, posibilidades de recuperación, aprovechamiento, comercialización y disposición final" ( $p$. 2).

Otra definición de GIRS la sugieren Choles (2013) basada en Tchobanoglous, G., Theisen, H., \& Vigil, S (2013), quien menciona que: "La Gestión Integral de Residuos Sólidos puede ser definida como la disciplina asociada al control de la generación, almacenamiento, recogida, transferencia y transporte, procesamiento
Aunque el Desarrollo Sostenible podría verse como una creación más del modelo económico actual para seguir explotando deliberadamente los servicios que ofrece la naturaleza, si es interesante, el análisis de las dimensiones antes descritas, quizás no como soportes al Desarrollo Sostenible, sino como soportes al desarrollo local que favorezca a las comunidades y no a un mercado global.

y evacuación de los residuos sólidos de una forma que armoniza con los mejores principios de la salud pública, de la economía, de la ingeniería, de la conservación de la estética, y de otras consideraciones ambientales y que también responde a las expectativas públicas" (p. 12).

Según las anteriores definiciones se podría decir que la GIRS se compone de un conjunto procedimientos y etapas, que involucran aspectos como el control de la generación o también llamada reducción en la fuente, la reutilización, reciclaje, y por último, la disposición final. A continuación, se especifican cada una de las etapas:

Control de la generación o Reducción en la fuente: La reducción en la fuente es la parte más importante dentro del proceso de 
la GIRS, pues al disminuir la cantidad de residuos que se genera, se evitan mayores complicaciones del proceso en etapas posteriores, principalmente en la disposición final. Para llevar a cabo un proceso eficaz del control en la generación, es de vital importancia que quienes fabrican los diferentes productos que se consumen a diario, se comprometan a elaborar productos con periodos de vida más largos y productos que no sean tóxicos para la salud humana y el medio ambiente, así mismo, los ciudadanos deben detallar las características del producto que va a consumir y sus posibles impactos y afectaciones.

Reutilización: Al igual que el proceso de control en la generación, la reutilización busca reducir la cantidad de residuos que se producen a diario en los centros poblados. El objetivo de la reutilización es alargar la vida útil de aquellos objetos que son utilizados para empacar o envasar lo que la población consume a diario, como, por ejemplo, botellas de plástico o vidrio, bolsas plásticas y papel, mediante la reutilización de estos en procesos similares a la inicial $\mathrm{u}$ otros procesos.

Reciclaje: Según Röben (2003), "El reciclaje es la actividad de recuperar los desechos sólidos al fin de reintegrarlos al ciclo económico, reutilizándolos o aprovechándose como materia prima para nuevos productos..." (p.4). La importancia del reciclaje no solo radica en que ayuda a disminuir la cantidad de desechos que van a los rellenos u otro tipo de proceso de disposición final, sino que busca hacerle frente al agotamiento de los recursos naturales.

Disposición final: Según el Decreto 838 de (2005), la disposición final "Es el proceso de aislar y confinar los residuos sólidos en especial los no aprovechables, en forma definitiva, en lugares especialmente seleccionados y diseñados para evitar la contaminación, y los daños o riesgos a la salud humana y al ambiente" (p. 1). El proceso de disposición final, es quizás, el más complejo dentro de la GIRS debido a la dificultad para encontrar sitios aptos, en el caso de los rellenos sanitarios, donde verter los residuos sobrantes que no entran en los procesos anteriormente mencionados.

Actualmente, con sus ventajas y desventajas, existen diferentes tecnologías para disposición final de residuos sólidos, tales como la Incineración con Valor Energético, Compostaje, Pirólisis y Gasificación, y Digestión Anaeróbica, sin embargo, la tecnología más utilizada es el relleno sanitario, entre otras cosas, por el bajo costo de operación, ventaja que no ofrecen las demás tecnologías mencionadas.

La implementación de un relleno sanitario trae consigo distintas problemáticas, entre ellas, la producción de lixiviados que resulta de la descomposición bioquímica de las basuras y del agua de infiltración (Collazos, 2001). Según el Ministerio de Medio Ambiente y Agua (2010), "La generación de lixiviado en un relleno sanitario está directamente relacionada con las condiciones climatológicas 
(precipitación, temperatura, humedad, evapotranspiración, radiación solar, etc.), propiedades del suelo, humedad de los residuos y la metodología de trabajo del relleno sanitario..." (p. 25).

\section{Localización - Asignación}

El economista alemán Von Thünen fue el primero en hablar sobre la localización de las actividades económicas, con el objetivo de determinar el precio de los productos, en este caso agrícolas, la renta y el costo de transporte, todos estos basados en la distancia entre el origen del producto y el destino (centros poblados). Para el año 1933 Walter Christaller desarrolló la teoría de los lugares centrales, la cual busca explicar, a partir de ciertos principios generales, la distribución y jerarquización de los espacios urbanos que prestan determinados servicios a la población de un área circundante en un espacio isótropo (Briñez, 2016).

En la actualidad se habla de modelos de localización- asignación que tienen en cuenta el uso de las herramientas como los sistemas de información geográficos - SIG para facilitar la toma de decisiones en cuanto a la localización de los servicios, según Buzai (2011) "estos modelos intentan evaluar las localizaciones actuales de los centros de servicio con base en la distribución de la demanda y la generación de alternativas para lograr una distribución espacial más eficiente y/o equitativa. Además, buscan las ubicaciones óptimas de localización y determinan las mejores vinculaciones de la demanda, entendida en términos de asignación” (p.112).

\section{Evaluación Multicriterio}

Localizar los equipamientos o infraestructuras que son usados para llevar a cabo las distintas actividades humanas, requiere tomar decisiones en cuanto que tan idóneo es un lugar para el emplazamiento de un determinado equipamiento. Durante este proceso, la pregunta principal es: ¿Dónde localizar?, a partir de su formulación, los tomadores de decisiones deberán determinar, procesar y evaluar distintos criterios que finalmente conduzcan a la obtención del lugar más "apto".

En la práctica, el objetivo de la EMC, es ayudar a los tomadores de decisiones a priorizar áreas, en el caso de la localización, donde se pueda emplazar un equipamiento, todo esto a partir del análisis de múltiples criterios tenidos en cuenta para el desarrollo del proyecto. Dentro de la EMC existen diferentes métodos que ayudan en la toma de decisiones, el más conocidos es el método de Análisis Jerárquico (AHP).

El método AHP es uno de los métodos más utilizados para llevar a cabo procesos de EMC en la toma de decisiones y su resultado en una evaluación se muestra como un índice que va de 0 a 1 . Para Muñoz y Romana (2016), "El AHP es uno de los métodos de decisión multiatributo más ampliamente utilizado. $\mathrm{Su}$ metodología se basa en comparación por 
parejas de la siguiente forma: ¿Cómo de importante es el criterio $\mathrm{C}_{\mathrm{i}}$ respecto al $\mathrm{C}_{\mathrm{j}}$ ? preguntas de este tipo se utilizan para establecer los pesos de los diferentes criterios y priorizar las alternativas. De esta forma, permite no solo valorar las diferentes alternativas, sino también establecer por comparaciones pareadas la importancia relativa de cada criterio respecto al resto, y establecer un vector de pesos" (p.32).

\section{MARCO NORMATIVO}

En Colombia, en materia normativa, se empezó a prestar mayor atención a las problemáticas medioambientales a partir de la constitución de 1991, dentro de esas problemáticas se encuentran inmersos los impactos ocasionados por los residuos sólidos que la población, en constante crecimiento genera, por tal razón, a partir de esa fecha, se empiezan a emitir leyes, decretos y resoluciones con el fin de tratar el manejo de los desechos y su disposición final en los diferentes entes territoriales de todo el país.

El decreto 1713 de 2002, reglamentó la ley 142 de 1994 y la ley 9 de 1993 en lo que concierne a la prestación del servicio público de aseo. Aunque este decreto en la actualidad no aplica debido a que el capítulo VIII que habla sobre la disposición final de los residuos, fue modificado por el decreto nacional 838 de 2005, que sentó un precedente al establecer pautas para llevar a cabo la disposición final de los desechos producidos, mediante la tecnología de relleno sanitario. Dentro de este decreto se establecen las características básicas de los sitios que serán usados para llevar a cabo la disposición final, la disposición regionalizada, las restricciones para ubicar rellenos sanitarios, los parámetros básicos para diseñar los rellenos sanitarios y los pasos a seguir para realizar la clausura de los vertederos oficiales.

El decreto 838 de 2005, modifica el capítulo VIII del decreto 1713 de 2002 en lo que tiene que ver con la disposición final. En el título I, capítulo II del decreto se establece el procedimiento, los criterios, la metodología, prohibiciones y restricciones para la localización de áreas para la disposición final de los residuos sólidos, es decir que otorga a los distritos, municipios o asociaciones de municipios (disposición regionalizada), las pautas y procedimientos para llevar a cabo dicho proceso.

Con la Ley 1450 de 2011 se expidió el Plan Nacional de Desarrollo 2010-2014, dentro de esta ley, en el artículo 251 se busca incentivar a los municipios donde se ubiquen rellenos sanitario y estaciones de transferencia de carácter regional. Justamente el decreto 920 de 2013 reglamentó este artículo y dio cabida a que en Colombia se empezará a hablar de sitios de disposición final de residuos sólidos de carácter regional. Bajo el decreto 1784 se busca el fortalecimiento regional en la gestión integral de los residuos sólidos, donde cada ente territorial podrá decidir dónde localizar su relleno sanitario, teniendo como base las características de los suelos y los instrumentos de 
ordenamiento territorial como los son los POT, PBOT o EOT de cada uno de los municipios. Dentro del mismo decreto también se declaran las áreas potenciales establecidas dentro de cada plan de ordenamiento, como áreas de interés público y social, así mismo, en el artículo 2.3.2.3.10 se categorizan los vertederos oficiales dependiendo de la cantidad diaria de residuos sólidos que estos reciben.

\section{Antecedentes sobre localización de rellenos sanitarios a nivel internacional y nacional}

A nivel internacional, múltiples estudios han acudido a los SIG y a la EMC para la localización de rellenos o vertederos sanitarios, los cuales han utilizado distintas metodologías y criterios. Estos han sido establecidos por los mismos autores o basándose en las normativas del país donde se realizó el trabajo de investigación. En Chile, Mena, Morales, Ormazábal y Gajardo (2010) establecieron criterios propios a partir de

\section{METODOLOGÍA}

La normatividad, el conocimiento detallado del territorio apoyado en la cartografía, el enfoque del Desarrollo Sostenible, los estudios previos realizados, y finalmente, la integración de estos grandes componentes por medio de herramientas de análisis multicriterio, entre las que se encuentra el proceso analítico jerárquico, responde a un enfoque sistémico y del estructuralismo en investigaciones previas que tenían en cuenta lo urbanístico, económico y ambiental, susceptibles de ser representados espacialmente, mientras que en Argentina Cardozo y Giménez (2012), para realizar su estudio, se basaron en la normativa vigente resolución $\mathrm{N}^{\circ} 282$ de la Secretaría del Ambiente de Argentina que ya tenía establecidos los criterios que deben ser tenidos en cuenta para la localización de los rellenos.

En Colombia ocurre algo similar, algunos autores establecieron criterios, mientras otros se basan en la normativa vigente. En la región Valle de San Nicolás; Valencia, Arias y Vanegas (2010), establecieron variables a partir de las dimensiones socioculturales, nivel de impacto ambiental y variables económicas, haciendo un análisis de la normativa colombiana, mientras que Gascón, Jiménez y Pérez (2015) se basaron en la ley colombiana para llevar a cabo el estudio de localización de rellenos sobre el Valle de Aburrá.

los cuales el mundo se fracciona en componentes que interactúan según sus propias características y de las de los otros componentes.

Se recurre a simplificar la realidad en las partes más determinantes para el problema en cuestión, en este caso la localización de un vertedero oficial o relleno sanitario. Un elemento crítico en el proceso es la selección de las variables, que eventualmente son los criterios a ser utilizados dentro de la EMC. La 
identificación de tales criterios responde a un ejercicio cuidadoso de revisión de literatura, en la que, basado en experiencias previas, se seleccionan aquellas que pueden ser las más determinantes a la hora de tomar la decisión.

De manera gráfica (Figura 1), se muestra el flujo de procesos y actividades llevados a cabo para la determinación de lugares potenciales para la localización del relleno sanitario en las Subregiones Norte y Oriente del Valle del Cauca. En la parte superior, paso 1, se encuentran las bases teóricas que sustentan la elección de los criterios generales y Subcriterios, dichas bases son: La caracterización del área de estudio, el enfoque del Desarrollo Sostenible y sus dimensiones, la metodología y procedimientos establecidos por la normativa colombiana, principalmente el decreto 838 de 2005 , yfinalmente, los estudios internacionales y nacionales que hacen referencia a la localización de rellenos sanitarios.
En el paso 2 se determinaron los criterios que fueron tenidos en cuenta para llevar a cabo la localización del relleno sanitario. La integración de las bases teóricas arrojó cuatro criterios generales: Físicoambientales, Socioeconómicos, Determinantes y de exclusión, así mismo, cada uno de estos, lo componen una serie de Subcriterios que fueron determinados en el paso 3, y que también surgen de la integración de las bases teóricas. En párrafos posteriores se analizan detalladamente y se realiza una clasificación de cada criterio y Subcriterio. Finalmente, en el paso 4, mediante el procesamiento de los datos en el software MCAS-S, se caracterizaron numéricamente cada uno de los Subcriterios, posteriormente mediante la herramienta "componer" contenida dentro del programa, se realizó la composición manual a partir de los datos obtenidos de la encuesta realizada a expertos, la cual tuvo como objetivo ayudar a definir los pesos de cada Subcriterio. 
Fuente: Elaboración propia.

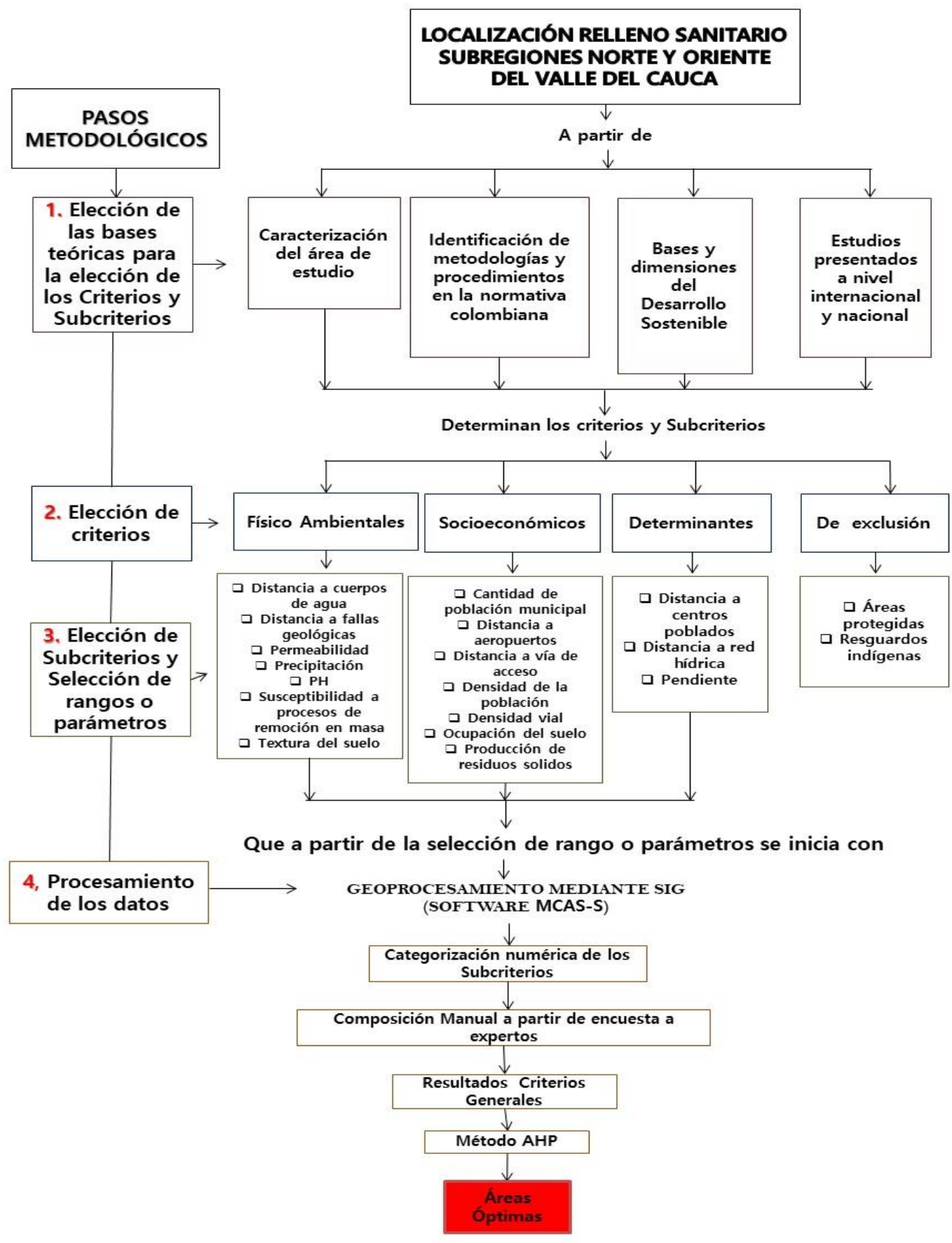

Figura 1. Esquema metodológico general. 


\section{IDENTIFICACIÓN Y CLASIFICACIÓN DE CRITERIOS GENERALES Y SUBCRITERIOS}

$\mathrm{Al}$ inicio de este estudio se definieron las bases teóricas del trabajo presentado, por tal razón se hizo una descripción detallada de cada uno de los componentes para posteriormente determinar los criterios generales y Subcriterios, por eso, la descripción y análisis del área de estudio por medio de cartografía y datos oficiales específicos del territorio, las dimensiones del desarrollo sostenible, las especificaciones de la normativa colombiana y finalmente, los estudios previos sobre la temática aquí tratada, ayudaron a definir las variables. Al integrar las bases teóricas se definió cuatro criterios generales, cada uno de estos compuestos por una serie de Subcriterios. Los Subcriterios se clasificaron en rangos o parámetros que se valoraron según la aptitud. En la Tabla 1 se presenta la escala de valoración que fue utilizada para evaluar los parámetros o rangos de cada uno de los Subcriterios específicos.

Tabla 1. Escala de valoración.

\begin{tabular}{|c|l|}
\hline $\begin{array}{c}\text { VALORACIÓ } \\
\text { N }\end{array}$ & \multicolumn{1}{|c|}{ DEFINICIÓN } \\
\hline 0 & $\begin{array}{l}\text { Definitivamente el parámetro o rango no cumple con } \\
\text { los requisitos para localizar un relleno sanitario }\end{array}$ \\
\hline 1 & $\begin{array}{l}\text { El parámetro o rango no cumple con los requisitos para } \\
\text { localizar un relleno sanitario }\end{array}$ \\
\hline 5 & $\begin{array}{l}\text { El parámetro o rango es medianamente apto para } \\
\text { localizar un relleno sanitario }\end{array}$ \\
\hline 10 & $\begin{array}{l}\text { El parámetro o rango es apto para localizar un relleno } \\
\text { sanitario }\end{array}$ \\
\hline
\end{tabular}

Fuente: Elaboración propia.

\section{Criterio Físico-ambiental}

En aras de encontrar el lugar más apto para localizar el relleno sanitario, el criterio físico-ambiental, según la propuesta del desarrollo sostenible, responde a la necesidad de preservar las fuentes hídricas, las cuales son el sustento de la población y de las actividades que esta realiza. El criterio también responde a la necesidad de encontrar terrenos con las mejores condiciones posibles para llevar a cabo el emplazamiento y así evitar afectaciones futuras al suelo. La variable general está compuesta por siete Subcriterios, los cuales se detallan en la Tabla 2 por medio de parámetros o rangos que se especifican a continuación. 
Tabla 2. Clasificación y valoración de subcriterios Físico-ambientales.

\begin{tabular}{|c|c|c|}
\hline SUBCRITERIO & $\begin{array}{c}\text { CLASIFICACIÓN DE } \\
\text { RANGOS O PARÁMETROS }\end{array}$ & VALOR \\
\hline \multirow{4}{*}{$\begin{array}{c}\text { Distancia a Cuerpos de } \\
\text { Agua } \\
\text { Fuente: Corporación Autónoma } \\
\text { Regional del Valle del Cauca-CVC. } \\
\text { ESC: } 1: 50.000\end{array}$} & $>2.000$ Metros & 10 \\
\hline & $501-2.000$ Metros & 5 \\
\hline & $61-500$ Metros & 1 \\
\hline & $0-60$ Metros & 0 \\
\hline \multirow{3}{*}{$\begin{array}{l}\text { Distancia A Fallas } \\
\text { Geológicas } \\
\text { Fuente: página web SIGOT } \\
\text { ESC: } 1: 100.000 \\
\end{array}$} & $>500$ Metros & 10 \\
\hline & 61-500 Metros & 5 \\
\hline & 0-60 Metros & 0 \\
\hline \multirow{3}{*}{$\begin{array}{c}\text { Permeabilidad } \\
\text { Fuente: Corporación Autónoma } \\
\text { Regional del Valle del Cauca-CVC. } \\
\text { ESC: } 1: 50.000\end{array}$} & Baja & 10 \\
\hline & Baja a moderadamente baja & 5 \\
\hline & Moderada a rápida & 0 \\
\hline \multirow{3}{*}{$\begin{array}{c}\text { PH } \\
\text { Fuente: Corporación Autónoma } \\
\text { Regional del Valle del Cauca-CVC. } \\
\text { ESC: } 1: 50.000\end{array}$} & $>6,0$ & 10 \\
\hline & ENTRE 5,5 Y 6,0 & 5 \\
\hline & $<5,5$ & 0 \\
\hline \multirow{3}{*}{$\begin{array}{c}\text { Precipitación } \\
\text { Fuente: Corporación Autónoma } \\
\text { Regional del Valle del Cauca-CVC. } \\
\text { ESC: } 1: 50.000\end{array}$} & $0-2000 \mathrm{~mm}$ & 10 \\
\hline & $2000-3000 \mathrm{~mm}$ & 5 \\
\hline & $>3000 \mathrm{~mm}$ & 0 \\
\hline \multirow{3}{*}{$\begin{array}{c}\text { Susceptibilidad a Procesos } \\
\text { De Remoción en Masa } \\
\text { Fuente: página web SIGOT } \\
\text { ESC: } 1: 100.000\end{array}$} & No susceptible & 10 \\
\hline & Baja & 5 \\
\hline & Moderada a alta & 0 \\
\hline \multirow{4}{*}{$\begin{array}{c}\text { Textura del Suelo } \\
\text { Fuente: Corporación Autónoma } \\
\text { Regional del Valle del Cauca-CVC. } \\
\text { ESC: } 1: 50.000\end{array}$} & $\begin{array}{l}\text { Areno-limo-arcillosas (franco } \\
\text { arcillosas) }\end{array}$ & 10 \\
\hline & $\begin{array}{c}\text { Limo - arcillosa (franco limoso, franco } \\
\text { limo-arcilloso y arcillo limosa) }\end{array}$ & 5 \\
\hline & $\begin{array}{c}\text { Arcillo limosa (Arcillo limosa y } \\
\text { arcillosa) }\end{array}$ & 1 \\
\hline & Areno limosa (franco arenosa) & 0 \\
\hline
\end{tabular}

Fuente: Elaboración propia, a partir de la cartografía base de la CVC y el IGAC.

Distancia a cuerpos de agua: El área de estudio se caracteriza por ser rica en fuentes hídricas, por tal razón, conociendo de la importancia de este servicio ecosistémico y de la gravedad que podría acarrear contaminar las fuentes de agua con los productos del relleno sanitario, este estudio se enfocara en su protección, mediante la búsqueda de áreas que se encuentren lo más alejadas posibles de los cuerpos de agua, que en la zona se componen de lagunas, pantanos, madrevieja, reservorios, ciénagas, entre otros. En definitiva, entre mayor sea la 
distancia a los cuerpos de agua, mejor valorada será el área donde se lleve a cabo el emplazamiento.

Distancia a fallas geológicas: Como medida de prevención, para la localización de cualquier equipamiento, incluido el relleno sanitario, se debe considerar el riesgo sísmico del sector con el fin de evitar afectaciones en la infraestructura del mismo, por esto es necesario que el área donde se lleve a cabo la localización del relleno esté lo más alejada posible.

Permeabilidad: Según Collazos (2001), "La permeabilidad permite calcular las cantidades de líquidos que pueden penetrar al subsuelo, medir los posibles daños a las aguas subterráneas o superficiales..." (p.36). Una permeabilidad alta puede ocasionar que a nivel interno, los lixiviados producidos por el relleno sanitario vayan a parar a las fuentes de agua.

PH: Para Collazos (2001), "el pH mide la capacidad de intercambio catiónico entre la basura y el suelo, y recomienda terrenos con $\mathrm{pH}>6.0$, se aceptan terrenos con $\mathrm{pH}$ entre 5.5 y 6.0 y no recomienda utilizar terrenos con $\mathrm{pH}<5.0$ "' (p.44).

Precipitación: A mayor cantidad de pluviosidad en un lugar, la dificultad para la operación de un relleno sanitario se dificulta, sobretodo porque a mayor cantidad de lluvias, los lixiviados al interior del relleno sanitario aumentan.

\section{Susceptibilidad a procesos de remoción}

en masa: Al igual que las problemáticas que pueden ocasionar los efectos sísmicos, la remoción en masa, por la forma del terreno, puede causar inconvenientes para la operación del relleno sanitario, por tal razón se recomiendan áreas que no sean susceptibles o que la susceptibilidad sea baja.

Textura del suelo: La textura permite identificar el tipo de material que predomina en lugares posibles donde se llevará a cabo la localización del relleno, para Collazos (2001), "Los mejores terrenos son entonces, los areno-limoarcillosos, se pueden aceptar en segundo término los limo-arcillosos, en tercer término, están los arcillo limosos y por último, es mejor evitar los terrenos areno limosos" (p.43).

\section{Criterio Socioeconómico}

El criterio Socioeconómico tiene en cuenta las características del territorio en cuanto a población e infraestructura. Se busca impactar lo menos posible a la población presente en la zona de estudio, pero a la vez se busca que el área donde se lleve a cabo el emplazamiento del relleno sanitario tenga una infraestructura adecuada que facilite las operaciones diarias. Este criterio general está compuesto por siete Subcriterios específicos, los cuales la mayoría surgen a raíz de los criterios y parámetros expuestos en el decreto 838 de 2005. En la Tabla 3 se detallan los parámetros o rangos de cada Subcriterio. 
Tabla 3. Clasificación y valoración subcriterios Socioeconómicos.

\begin{tabular}{|c|c|c|}
\hline SUBCRITERIO & $\begin{array}{c}\text { CLASIFICACIÓN DE } \\
\text { RANGOS O } \\
\text { PARÁMETROS } \\
\end{array}$ & VALOR \\
\hline \multirow{3}{*}{$\begin{array}{c}\text { Densidad de la Población } \\
\text { Fuente: DANE, } 2005\end{array}$} & 11-50 HAB/KM2 & 10 \\
\hline & 51-100 HAB/KM2 & 5 \\
\hline & 101-100 HAB/KM2 & 0 \\
\hline \multirow{4}{*}{$\begin{array}{c}\text { Cantidad de Población Municipal } \\
\text { Fuente: DANE, } 2005\end{array}$} & 100.0001-500.000 Hab & 10 \\
\hline & 20.0001-50.000 Hab & 5 \\
\hline & $10.0001-20.000 \mathrm{Hab}$ & 1 \\
\hline & $<=10.000 \mathrm{Hab}$ & 0 \\
\hline \multirow{3}{*}{$\begin{array}{c}\text { Distancia a Aeropuertos } \\
\text { Fuente: IGAC } \\
\text { ESC: } 1: 100.000\end{array}$} & $>13 \mathrm{KM}$ & 10 \\
\hline & $3,1 \mathrm{~km}-13 \mathrm{KM}$ & 5 \\
\hline & $0-3 \mathrm{KM}$ & 0 \\
\hline \multirow{4}{*}{$\begin{array}{c}\text { Distancia a Vía de Acceso } \\
\text { Fuente: IGAC } \\
\text { ESC: } 1: 100.000\end{array}$} & 0-10 Metros & 10 \\
\hline & 10,1-100 Metros & 5 \\
\hline & 100,1-500 Metros & 1 \\
\hline & $>500$ & 0 \\
\hline \multirow{3}{*}{$\begin{array}{l}\text { Densidad Vial } \\
\text { Fuente: IGAC } \\
\text { ESC 1:100.000 }\end{array}$} & $1,01-2 \mathrm{KM}$ & 10 \\
\hline & $0,51-1,0 \mathrm{KM}$ & 5 \\
\hline & $0-0,5 \mathrm{KM}$ & 0 \\
\hline \multirow{3}{*}{$\begin{array}{c}\text { Producción de Residuos Sólidos } \\
\text { Fuente: Superservicios } 2015\end{array}$} & >30,1 Ton/día & 10 \\
\hline & 10,1-30 Ton/día & 5 \\
\hline & 0,1-10 Ton/día & 0 \\
\hline \multirow{3}{*}{$\begin{array}{c}\text { Ocupación del Suelo } \\
\text { Fuente: Corporación Autónoma Regional del Valle } \\
\text { del Cauca-CVC. } \\
\text { ESC: } 1: 50.000\end{array}$} & Suelo Rural & 10 \\
\hline & Suelo suburbano & 5 \\
\hline & Suelo urbano y de protección & 0 \\
\hline
\end{tabular}

Fuente: Elaboración propia, a partir del Censo DANE (2005), los datos de Superservicios (2015), la cartografía base del IGAC y la CVC.

Cantidad de población municipal: La cantidad de población se determinó por municipio, para este caso de estudio se le asignó más peso a los municipios con una población superior, puesto que es importante que el relleno sanitario está localizado cerca de los lugares donde más se produzca residuos sólidos. 
Densidad: La densidad de población permite identificar las zonas o áreas más pobladas por kilómetro cuadrado. Para evitar mayores impactos a la población, se le asignó más peso a aquellas zonas donde la cantidad de población por kilómetro cuadrado sea la más baja.

Distancia a aeropuertos: Los rellenos sanitarios por lo general atraen a las aves de rapiña, por lo que estos sitios de disposición final, deben estar a una distancia importante de los aeropuertos con el fin de evitar posibles accidentes.

\section{Distancia a la vía de acceso y Densidad vial: La localización de un relleno sanitario, sobretodo de tipo regional, requiere de buenas vías de acceso para transportar los residuos sólidos desde los centros poblados hasta el sitio de disposición final. Para este proceso es necesario conocer la calidad de las vías presentes en el área de estudio y la cantidad.}

Ocupación del suelo: Como variable fundamental de la localización de un equipamiento, es necesario e imprescindible conocer la ocupación del suelo en el cual se llevará a cabo el proyecto. En el suelo urbano y suelos de protección está prohibido llevar a cabo la localización de un vertedero, por lo tanto quedan las opciones del suelo rural y el suelo suburbano. En el suelo rural es posible encontrar diferentes actividades, entre ellas, actividad agrícola, ganadería, tierras forestales para la extracción de madera, etc.

Producción de residuos sólidos: Para este estudio, se ha tenido en cuenta la producción de residuos por tonelada que produce cada municipio del área analizada, pues es pertinente que la localización de un relleno sanitario se de los más cerca posible al centro poblado que más residuos produce, ya que esto disminuiría los costos de transporte.

Es preciso aclarar que los parámetros o rangos de las variables como la densidad de población, la cantidad de población municipal, distancia a vía de acceso, densidad vial y producción de residuos sólidos, fueron calculados a partir de lo expuesto en la descripción del área de estudio.

\section{Criterios Determinantes}

El criterio Determinante tiene como objetivo proteger las redes hídricas, ayudar a definir la aptitud del terreno donde se localizara el relleno sanitario, dándole preponderancia a la pendiente, y por último, proteger a la población de los posibles impactos ocasionados por el relleno, buscando áreas que se encuentren los más alejadas posible de los centro poblados. El criterio está compuesto por tres Subcriterios, los cuales se describen en los párrafos siguientes. En la Tabla 4 se especifican los parámetros o rangos y la valoración de cada uno. 
Tabla 4. Clasificación y valoración Subcriterios determinantes.

\begin{tabular}{|c|c|c|}
\hline CRITERIO & $\begin{array}{c}\text { CLASIFICACIÓN DE } \\
\text { RANGOS O PARÁMETROS }\end{array}$ & VALOR \\
\hline \multirow{4}{*}{$\begin{array}{c}\text { Pendiente } \\
\text { Fuente: Corporación Autónoma Regional del } \\
\text { Valle del Cauca-CVC. } \\
\text { ESC: } 1: 50.000 \\
\end{array}$} & $3,1 \%-12 \%$ & 10 \\
\hline & $12,1 \%-25 \%$ & 5 \\
\hline & $0-3 \%$ & 0 \\
\hline & $>25 \%$ & 0 \\
\hline \multirow{4}{*}{$\begin{array}{c}\text { Distancia A Centros } \\
\text { Poblados } \\
\text { página web SIGOT } \\
\text { ESC: } 1: 00.000 \\
\end{array}$} & 2001-5000 Metros & 10 \\
\hline & 5001-10000 Metros & 5 \\
\hline & 0-2000 Metros & 0 \\
\hline & $>10000$ Metros & 0 \\
\hline \multirow{4}{*}{$\begin{array}{c}\text { Distancia a Red Hídrica } \\
\text { Fuente: Corporación Autónoma } \\
\text { Regional del Valle del Cauca-CVC. } \\
\text { ESC: } 1: 50.000 \\
\end{array}$} & $>2000$ Metros & 10 \\
\hline & 501-2000 Metros & 5 \\
\hline & 51-500 Metros & 1 \\
\hline & 0-50 Metros & 0 \\
\hline
\end{tabular}

Fuente: Elaboración propia

Pendiente: Para la operación del relleno sanitario es necesario que este se localice en áreas, Según Collazos (2001), con "pendiente entre el 3\% y 12\%; no debe estar ubicado en sitios con pendientes mayores del $25 \%$ por las dificultades de operación; los que tienen pendiente menores del 3\%, generalmente son difíciles de manejar por las aguas de escorrentía y los lixiviados". En base a lo expuesto por Peñalosa y por las características del área de estudio, la pendiente es un criterio determinante, pues es prácticamente imposible llevar a cabo la localización de un relleno en pendientes superiores al $25 \%$.

Distancia a centros poblados: Un relleno sanitario no puede estar cerca a los centros poblados por problemáticas de tipo sanitarias, ni tampoco tan alejado por los costos que acarrea el transporte de los residuos. El decreto 838 de 2005 establece un rango de prioridad que va desde los 2 $\mathrm{km}$ a los $5 \mathrm{~km}$, siendo este, el más conveniente para llevar a cabo la localización.

Distancia a cuerpos hídricos: El área de estudio se caracteriza por la presencia de una red hídrica importante, compuesta por ríos, quebradas, arroyos, cañadas etc., que deben ser preservada y protegida de los productos contaminantes del relleno sanitario.

Aunque cada uno de estos Subcriterios podrían estar inmersos dentro de los criterios Físico-ambientales o Socioeconómicos, fue importante destacarlos en un criterio general aparte donde las condiciones físicas del territorio, la protección de la red hídrica y de la población, priorizaran áreas posibles donde llevar a cabo el emplazamiento del 
relleno sanitario, todo esto siguiendo los parámetros del desarrollo sostenible que hace énfasis en la protección a la población y al medio ambiente, es decir, al territorio en su conjunto.

\section{Criterio de Exclusión}

Los criterios de exclusión, expuestos la Figura 2, son aquellos donde bajo ninguna circunstancia puede llevarse a cabo la localización de un relleno sanitario, para este estudio, las áreas protegidas como parques nacionales, reservas forestales, entre otras, no podrán ser tenidas en cuenta como terrenos posibles. Los resguardos indígenas, catalogados como territorios especiales, amparados bajo la normativa colombiana, tampoco podrán catalogarse o destinarse para el relleno sanitario. Los dos Subcriterios seleccionados dentro del criterio general no fueron clasificados ni procesados como en los casos anteriores, sino que ya en los resultados se sobrepuso la capa del criterio para así evitar tomar las áreas que fueron delimitadas como zonas de exclusión.

Fuente: Elaboración propia a partir de datos obtenidos de la CVC, 2018.

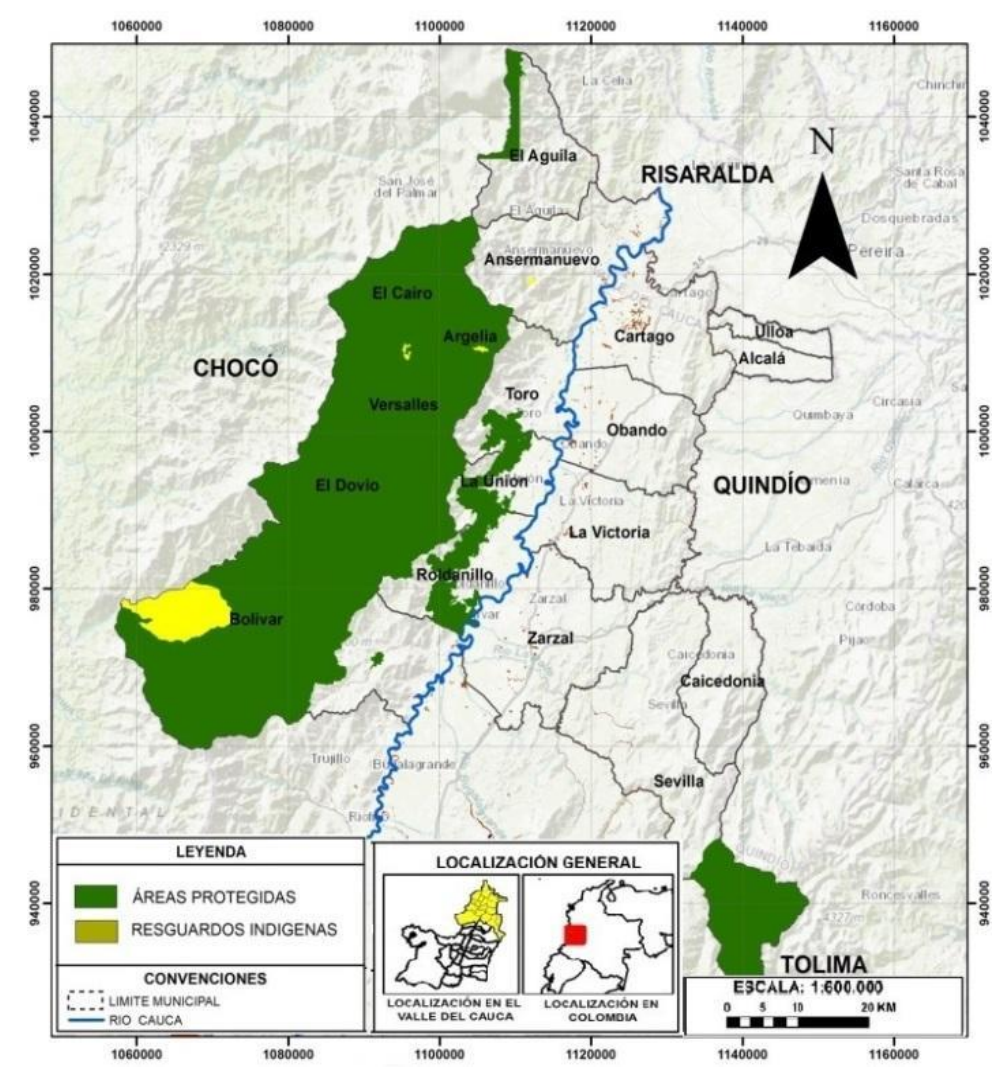

Figura 2. Criterios de exclusión. 


\section{PROCEDIMIENTOS Y RESULTADOS PRELIMINARES}

Realizado el trabajo de clasificación de criterios, clasificación de parámetros y valoración de los Subcriterios, se procedió a realizar el geoprocesamientos en el programa MCAS-S donde se obtuvieron resultados preliminares de la unión de los distintos Subcriterios y que derivaron en la obtención de los criterios generales. Mediante la opción "Categorizar", de tipo "Numérico", se categorizó en el programa cada uno de los Subcriterios pertenecientes a los criterios generales y se les dio, de manera manual, la valoración respectiva ya especificada en las tres tablas anteriores.

La Figura 3 es un ejemplo y corresponde al Subcriterio "Distancia a cuerpos de agua", el cual se divide en cuatro parámetros. En la serie de colores que va de negro a blanco y termina en azul, se muestra la distancia al cuerpo de agua, El color negro representa aquellas zonas que están a más de 2.000 metros, mientras que el color azul representa aquellas zonas que están entre 0 y 60 metros de distancia.

Fuente: Elaboración propia a partir de geoprocesamiento en MCAS-S.

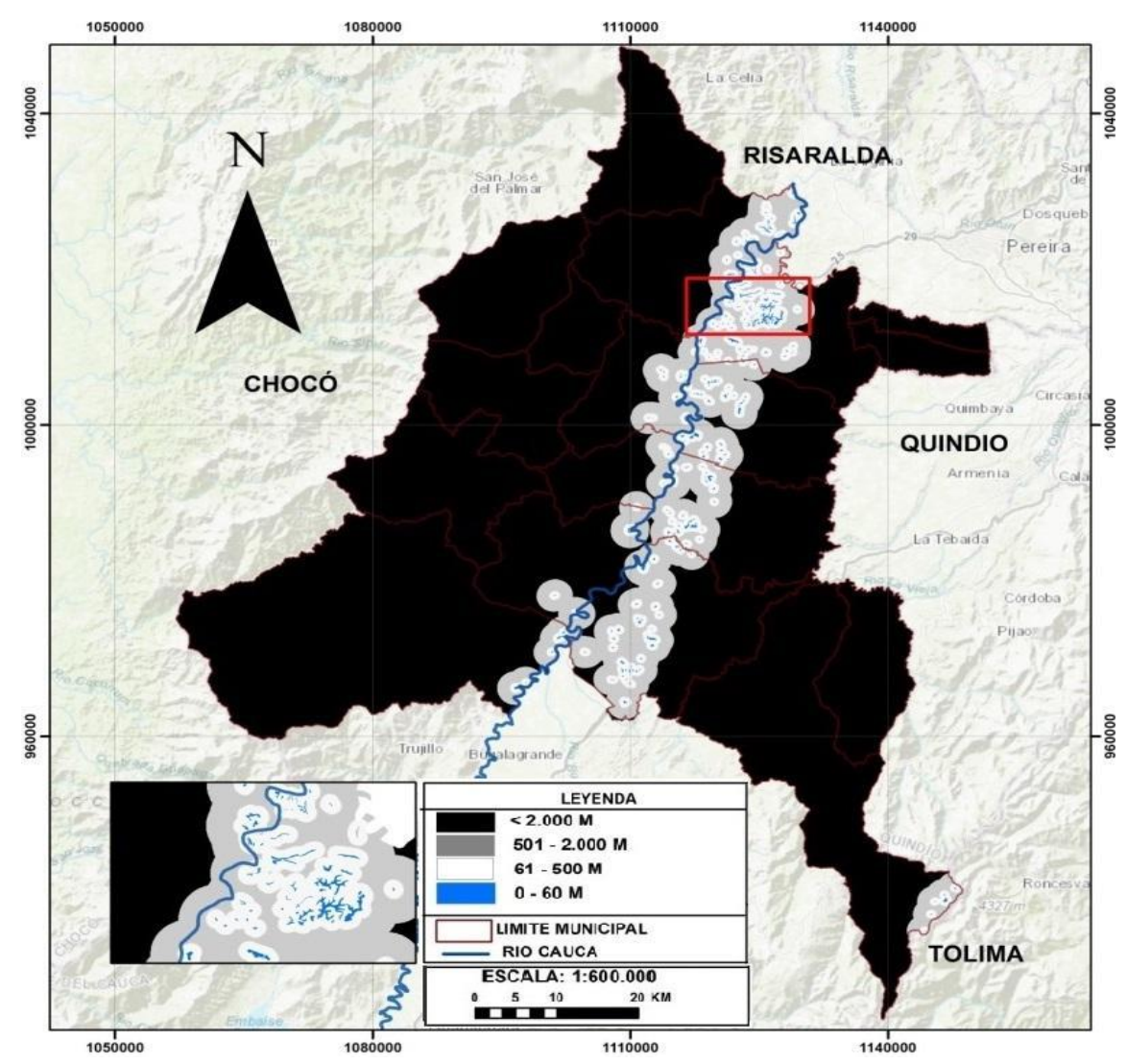

Figura 3. Clasificación por parámetros del Subcriterio "Distancia a cuerpos de agua". 
Después de realizar la categorización de tipo numérico en el programa, se procedió a realizar de manera manual, mediante la opción "componer", la unión de cada subcriterio, para obtener como resultados previos los criterios generales. Para realizar el procedimiento, se realizado una encuesta a diferentes expertos para que, según sus conocimientos previos, valorará la importancia de cada criterio específico determinado.

\section{Encuesta a expertos}

Para obtener el peso de cada uno de los Subcriterios, se realizó una encuesta a diferentes expertos en distintos campos, con conocimientos previos en procesos de localización de equipamientos, entre ellos, rellenos sanitarios. En total se realizaron 9 encuestas que involucraron a los siguientes profesionales: 2 ingenieros topográficos que laboran como consultores en el área de los SIG, 1 biólogo que trabaja como docente en la Universidad del Valle, 1 ingeniero agrícola que se desempeña como docente en la Universidad del Valle, 2 geógrafos asistentes en proyectos de investigación de la Universidad del Valle relacionados con la gestión del riesgo, 1 economista asistente en proyectos de investigación relacionados con el transporte, y finalmente, 2 tecnólogos en manejo y conservación de suelos y aguas, para un total de 9 expertos.

En las Tablas 5 y 6 se detalla el puntaje promedio obtenido en la encuesta después de que se pidiera a cada evaluador determinar el peso e importancia de cada Subcriterio en una escala de 1 a 10, donde 1 significaba menor importe y 10 muy importante. En la indagación, los Subcriterios fueron introducidos en dos criterios generales, los Físico-ambientales y los socioeconómicos. Para evitar confusiones en el encuestado se evitó exponer los criterios determinantes, es por eso que estos aparecen dentro de los dos criterios expuestos y se marcan con un asterisco en los cuadros que se muestran a continuación.

Tabla 5. Pesos Subcriterios Físico-ambientales.

\begin{tabular}{|c|c|}
\hline & PESO \\
CRITERIO & PROMEDIO ENCUESTA \\
\hline *Distancia Red Hídrica & 9 \\
\hline Distancia a Cuerpos De Agua & 8,5 \\
\hline Textura Del Suelo & 8,75 \\
\hline Distancia a Fallas Geológicas & 9 \\
\hline Susceptibilidad Remoción en Masa & 8,75 \\
\hline *Pendiente & 7 \\
\hline PH & 8,75 \\
\hline Precipitación & 8,5 \\
\hline Permeabilidad & \\
\hline
\end{tabular}

Fuente: Elaboración propia. 
Tabla 6. Pesos Subcriterios Socioeconómicos.

\begin{tabular}{|c|c|}
\hline CRITERIO & PESO ENCUESTA \\
\hline Distancia a Aeropuertos & 7 \\
\hline Distancia a la Vía de Acceso & 8,25 \\
\hline Densidad Vial & 7,25 \\
\hline Densidad de la Población & 8,75 \\
\hline Población Municipal Actual & 7,75 \\
\hline *Distancia a Centros Poblados & 8,75 \\
\hline Producción de Residuos Sólidos & 7,5 \\
\hline Tipo de Suelo & 8 \\
\hline
\end{tabular}

Fuente: Elaboración propia.

En la encuesta también se preguntó sobre el peso de cada uno de los criterios generales expuestos, sin embargo, en esta parte se pidió al encuestado que en una escala de 1 a 10 determinara el peso de cada criterio, pero que la suma de ambos fuera igual a 10. Los datos obtenidos fueron tenidos en cuenta para llevar a cabo la evaluación de los criterios generales en un proceso posterior. En la Tabla 7 se muestran los resultados arrojados.

Tabla 7. Pesos criterios generales expuestos en la encuesta.

\begin{tabular}{|c|c|}
\hline CRITERIO & PESO \\
& \\
\hline $\begin{array}{c}\text { Criterio } \\
\text { Socioeconómico }\end{array}$ \\
\hline $\begin{array}{c}\text { Criterio Físico- } \\
\text { Ambiental }\end{array}$ \\
\end{tabular}

Fuente: Elaboración propia. 


\section{Composición manual}

Esta opción contenida dentro del software MCAS-S permite definir los pesos de cada variable o subcriterio de manera manual cuando ya se tienen definidos los datos, en este caso los datos arrojados de la encuesta. Aplicando dos operaciones básicas como la multiplicación y suma de las variables, se obtienen diferentes clases, que para este caso de estudio, se definieron 5 , cada una representada por un color diferente.

En la Figura 4, en el resultado de los criterios Físico-ambientales se muestra señalado en rojo una gran cantidad de áreas, en las cuales, según este criterio podría llevarse a cabo una localización óptima. Las zonas en rojo representan aquellas áreas más idóneas para la localización de un relleno sanitario, mientras las áreas de color verde son las menos aptas, según los valores que para este caso van desde 53 a 516. Para el criterio Físico-ambiental en MCAS-S se definieron 5 clases a partir de la sumatoria de los resultados obtenidos de las variables o Subcriterios.

Fuente: Elaboración propia a partir de geoprocesamiento en MCAS-S.

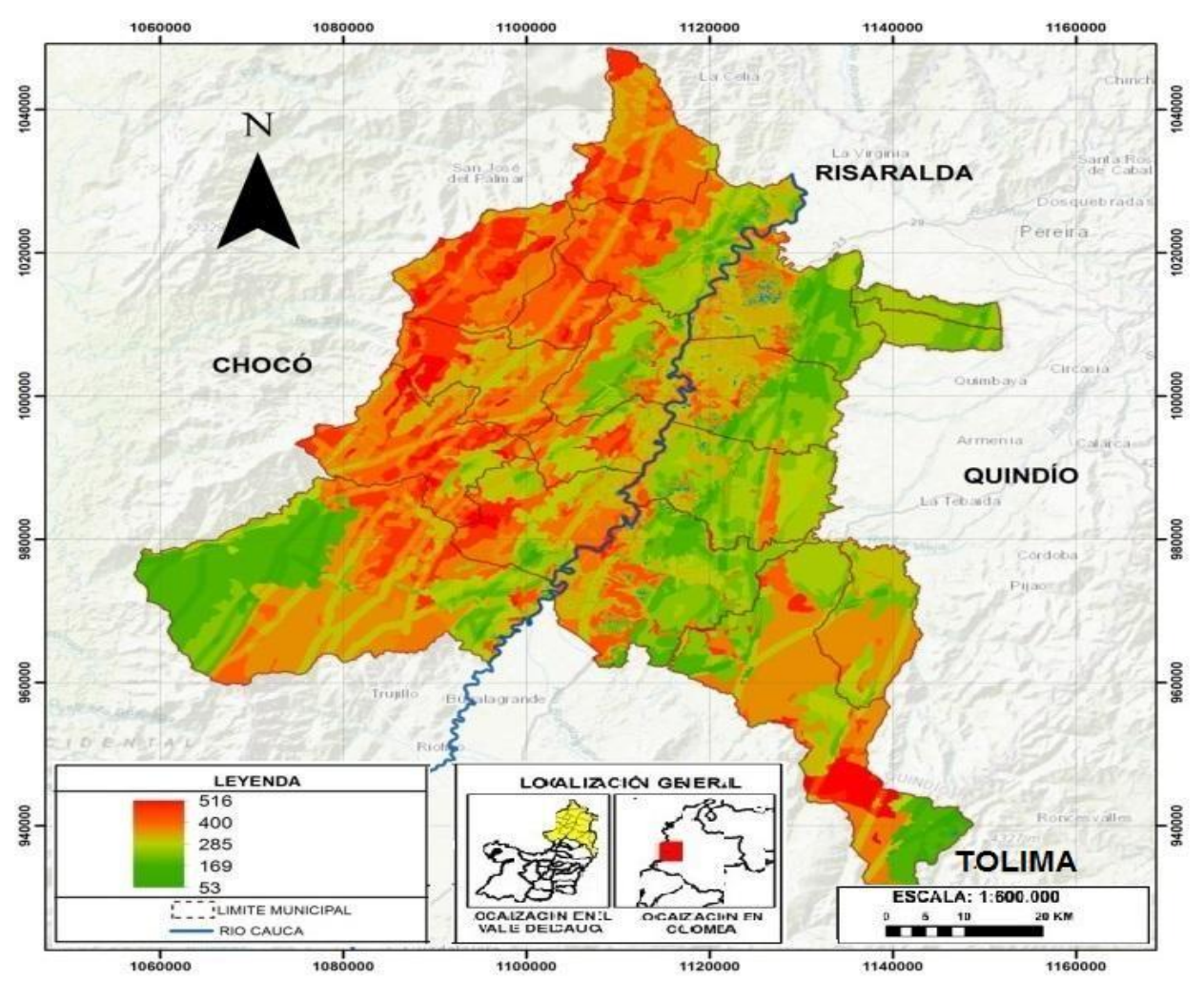

Figura 4. Unión criterios Físico-ambientales. 
En la Figura 5, criterios socioeconómicos, el número de áreas marcadas en rojo son bastante reducidas en comparación con el criterio anterior. Para este criterio también se definieron cinco clases. La sumatoria de los resultados de las variables van en una escala de 115 a 441, donde el primer valor representa las áreas con la menor valoración y el segundo valor representa las áreas con el puntaje más alto. En esta figura se observa en la parte inferior izquierda, municipio de Bolívar, que existe una zona en blanco, esto indica que la zona carece de información en uno de los Subcriterios que fueron integrados, precisamente el Subcriterio "Distancia a vías de acceso". Esta falta de información en esa parte del área de estudio implica también que el mapa final de resultados tendrá el espacio vacío.

Fuente: Elaboración propia a partir de geoprocesamiento en MCAS-S.

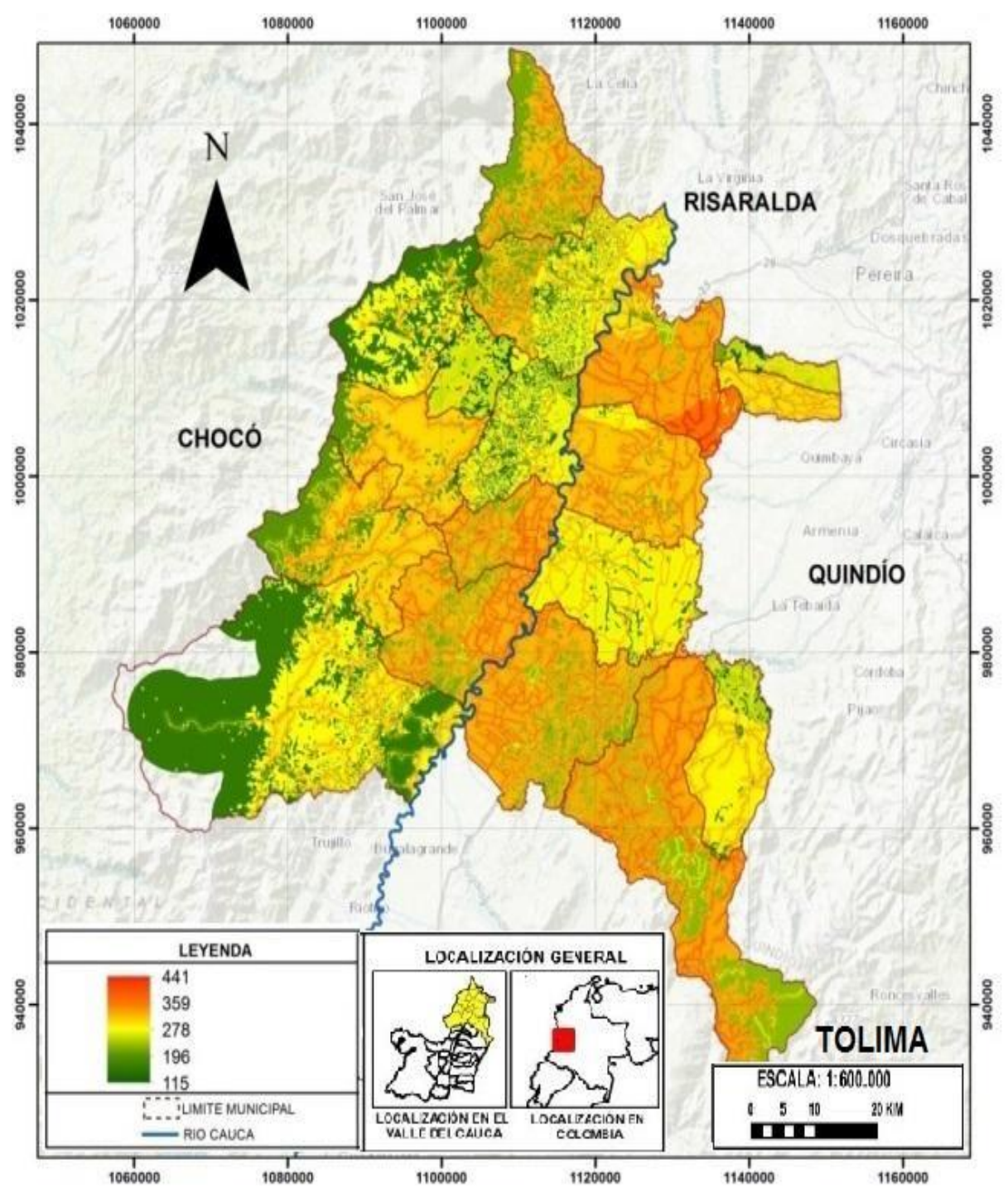

Figura 5. Unión Criterios Socioeconómicos 
En la Figura 6, criterios determinantes, al igual que en los dos casos anteriores, se determinaron cinco clases donde la sumatoria de los resultados de las variables, después de la composición manual, van desde 0 a 250, cero representa las áreas con la valoración más baja y 250 las áreas con la valoración más alta.

Fuente: Elaboración propia a partir de geoprocesamiento en MCAS-S.

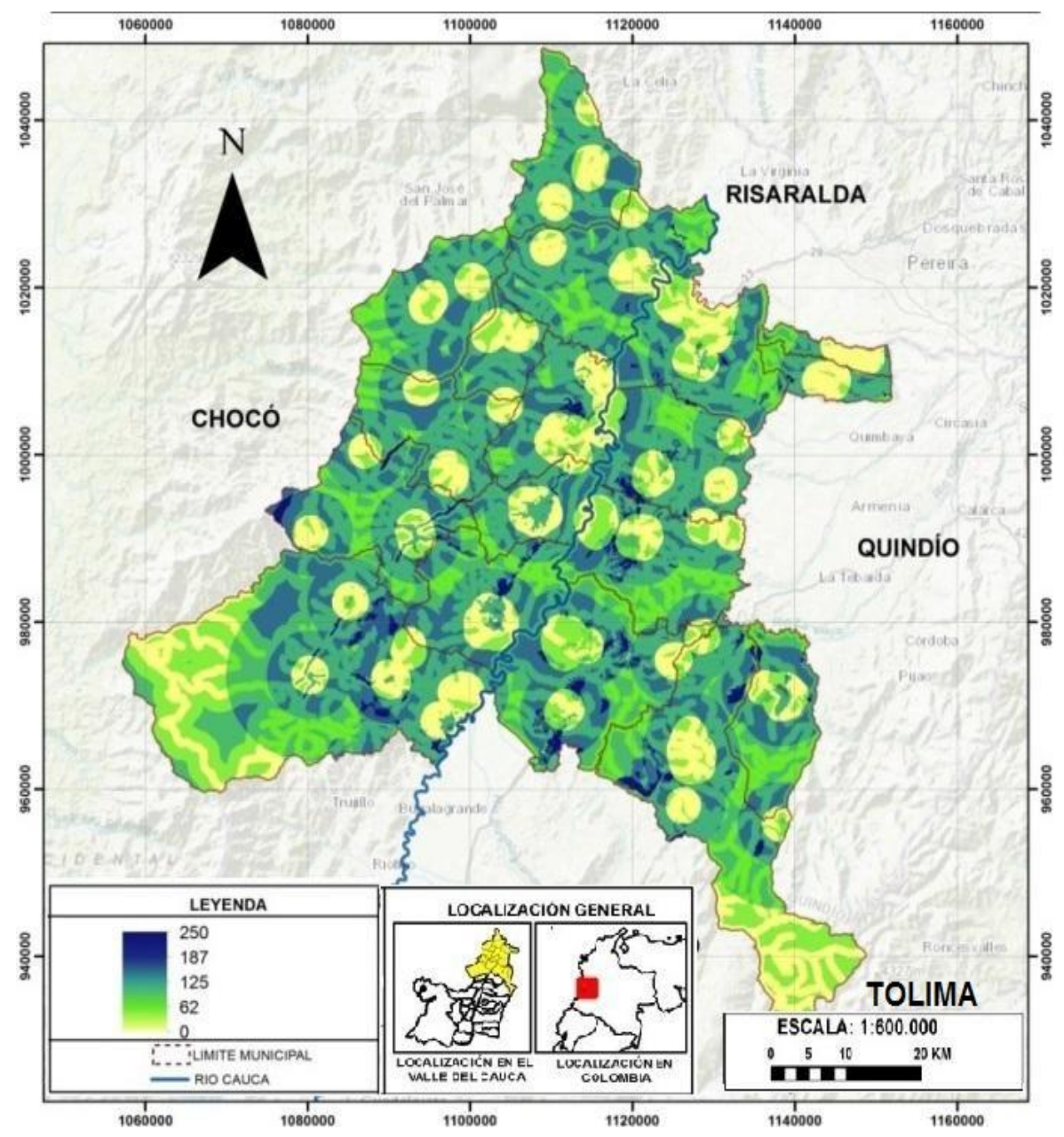

Figura 6. Unión Criterios Determinantes.

\section{Composición de los criterios generales}

A partir de la composición de los Subcriterios específicos se obtuvieron los resultados por criterio general, en este punto, se realizó la composición del criterio Físico-ambiental con el Socioeconómico. Después de la composición manual, la sumatoria de todos los Subcriterios de ambos criterios 
generales representan valores, en una escala que van desde 1.131 hasta 4.537, donde 1.131 representa las áreas con menor aptitud para localizar el relleno sanitario, mientras los valores que se acerquen a 4.537 representan las áreas más adecuadas. En la Figura 7 se muestra los resultados obtenidos de la composición.

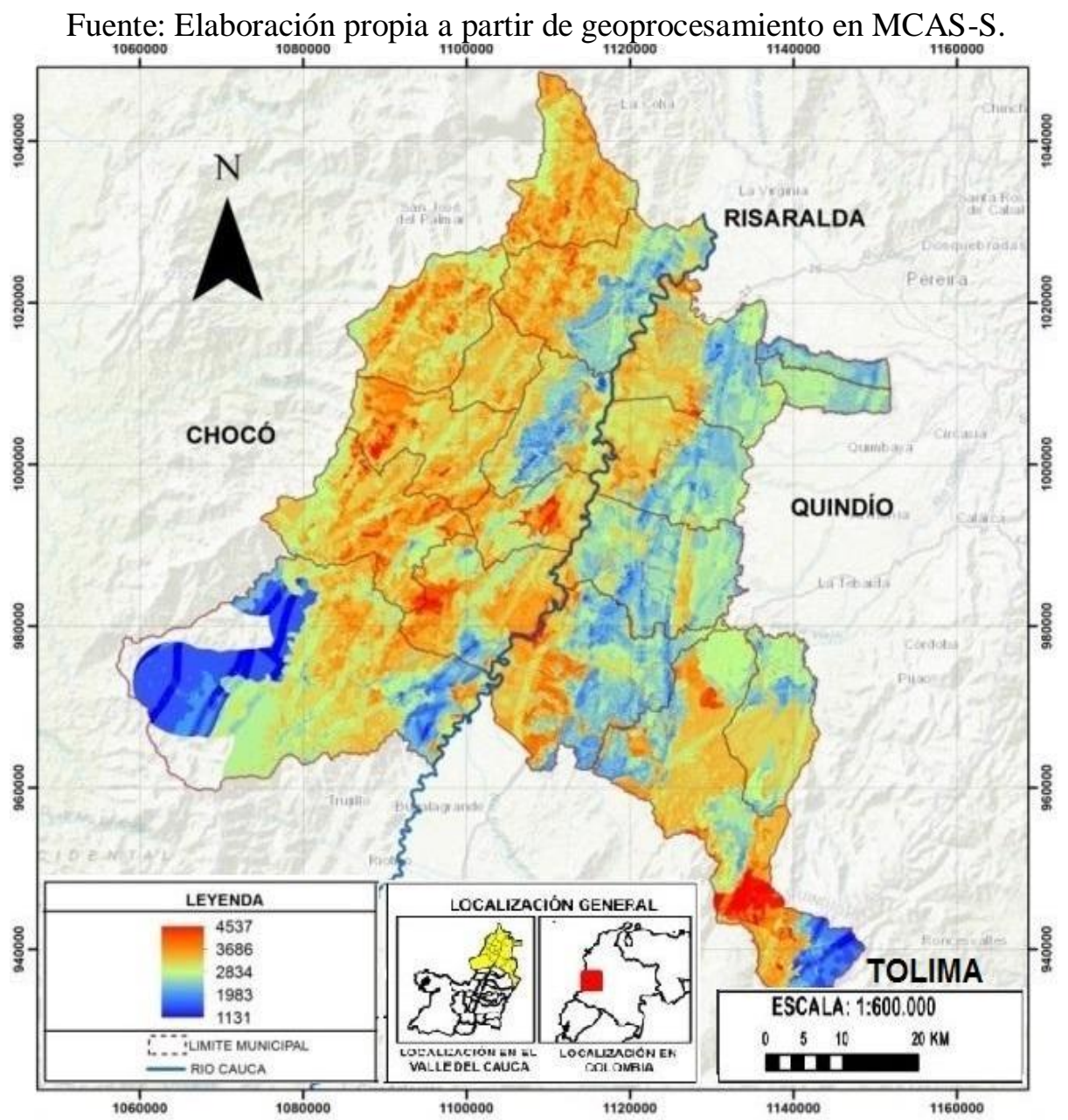

Figura 7. Unión criterios generales

\section{Aplicación del método AHP}

El método AHP, como herramienta contenida dentro de MCAS-S, fue aplicado teniendo presente el resultado de la composición entre los criterios Físicoambientales y socioeconómicos, con el criterio determinante. $\mathrm{Al}$ realizar el procedimiento, al criterio determinante dentro de la escala anteriormente expuesta, se le asignó un valor de 3 , que significa 
"débilmente más importante que". Siguiendo el enfoque del desarrollo sostenible, el criterio determinante busca la protección del espacio físico, de las fuentes de agua y de la población, por lo tanto fue preciso, dentro de la evaluación, asignarle un peso relativamente mayor que a los demás criterios. El método efectúa, al igual que el manual, operaciones de multiplicación y suma, sin embargo, en este caso los resultados se muestran en una escala que va de $0-1$, donde 0 es el lugar menos apto y 1 el área más apta para localizar un relleno sanitario.

\section{RESULTADOS}

En la Figura 8 se muestran los criterios de exclusión ya integrados y los resultados obtenidos después de realizado todo el geoprocesamiento en MCAS-S a partir de la aplicación del método AHP. En color azul oscuro se muestran las áreas menos aptas, las cuales tienen puntajes que van de 0 a 0.193 , esto significa que dichas zonas son las menos propicias para llevar a cabo la localización del relleno sanitario. Posteriormente aparecen áreas de color cian con valores que van de 0.193 a 0.386 , esto significa que dichas áreas tienen serias limitaciones y por tanto, no es viable llevar a cabo el emplazamiento del relleno en estas zonas. El color verde claro con valores que van de 0.386 a 0.580 representa aquellas áreas que aunque tienen limitaciones, podrían considerarse como opción para llevar a cabo la localización.

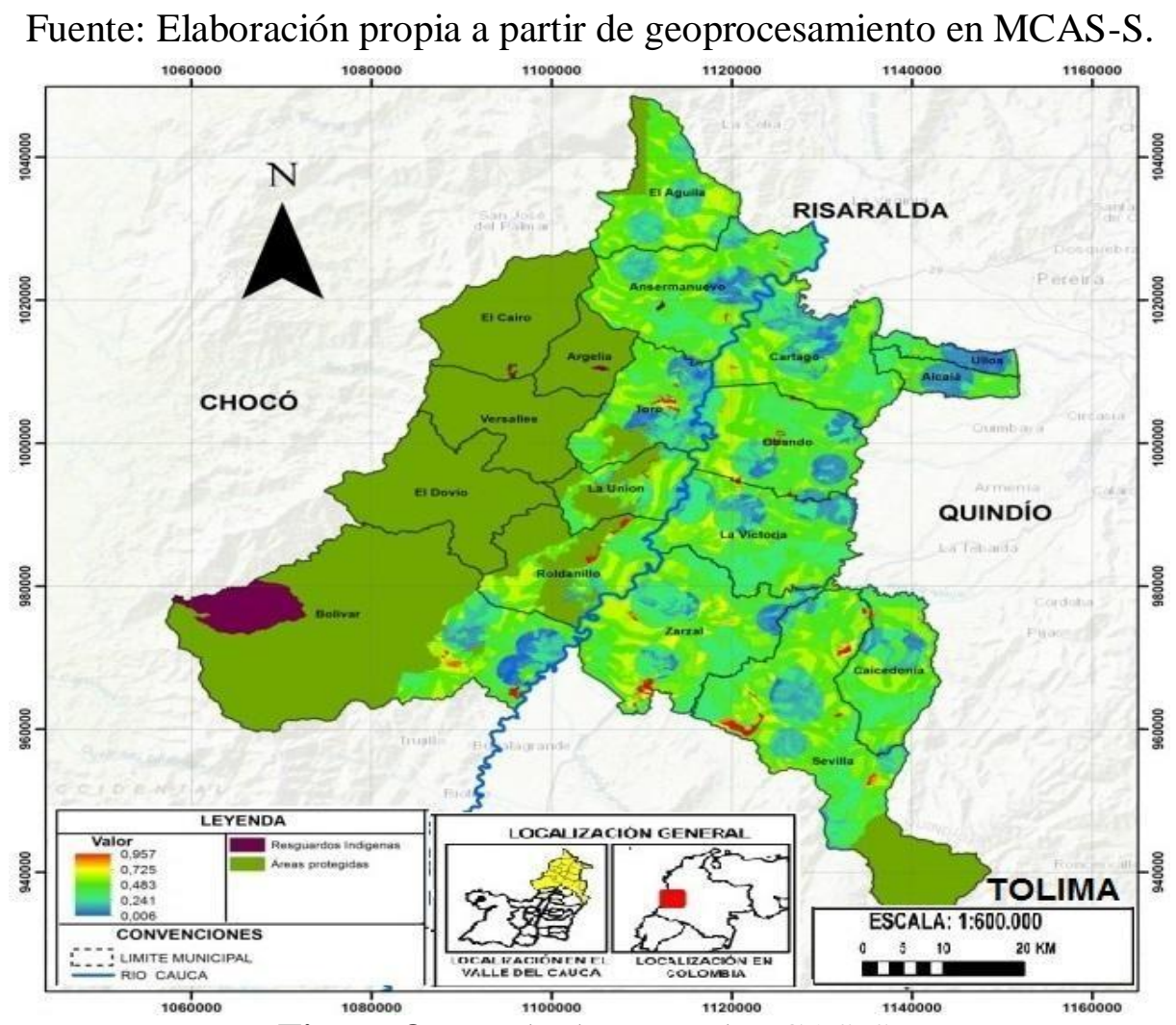

Figura 8. Resultado general MCAS-S. 
En color amarillo, con valores que van de 0.580 a 0.773 , se muestran aquellas áreas que podrían considerarse aptas, y finalmente, en color rojo se muestran aquellas áreas que según el estudio son aptas para localizar el relleno sanitario, dichas áreas tienen valores que van de 0.773 a 0.957 . Es preciso aclarar que entre mayor sea el puntaje, el área se considera más apta, pues significa que cumple con los requerimientos y parámetros exigidos de cada uno de los Subcriterios integrados para llevar a cabo la localización del relleno sanitario.

\section{Elección de áreas óptimas}

Una vez realizada la integración de los diferentes componentes que inciden en la decisión de localización del relleno, la cual se logró mediante la herramienta MCAS$\mathrm{S}$, se identificaron dos posibles áreas, las cuales obtuvieron la puntuación más alta dentro del ejercicio realizado. En la Figura 9 se muestra la localización de las áreas seleccionadas como óptimas dentro de la zona de estudio. El área 1 se encuentra localizada en el municipio de Obando, mientras que el área 2 en el municipio de Toro.

Fuente: Elaboración propia a partir de geoprocesamiento en MCAS-S.

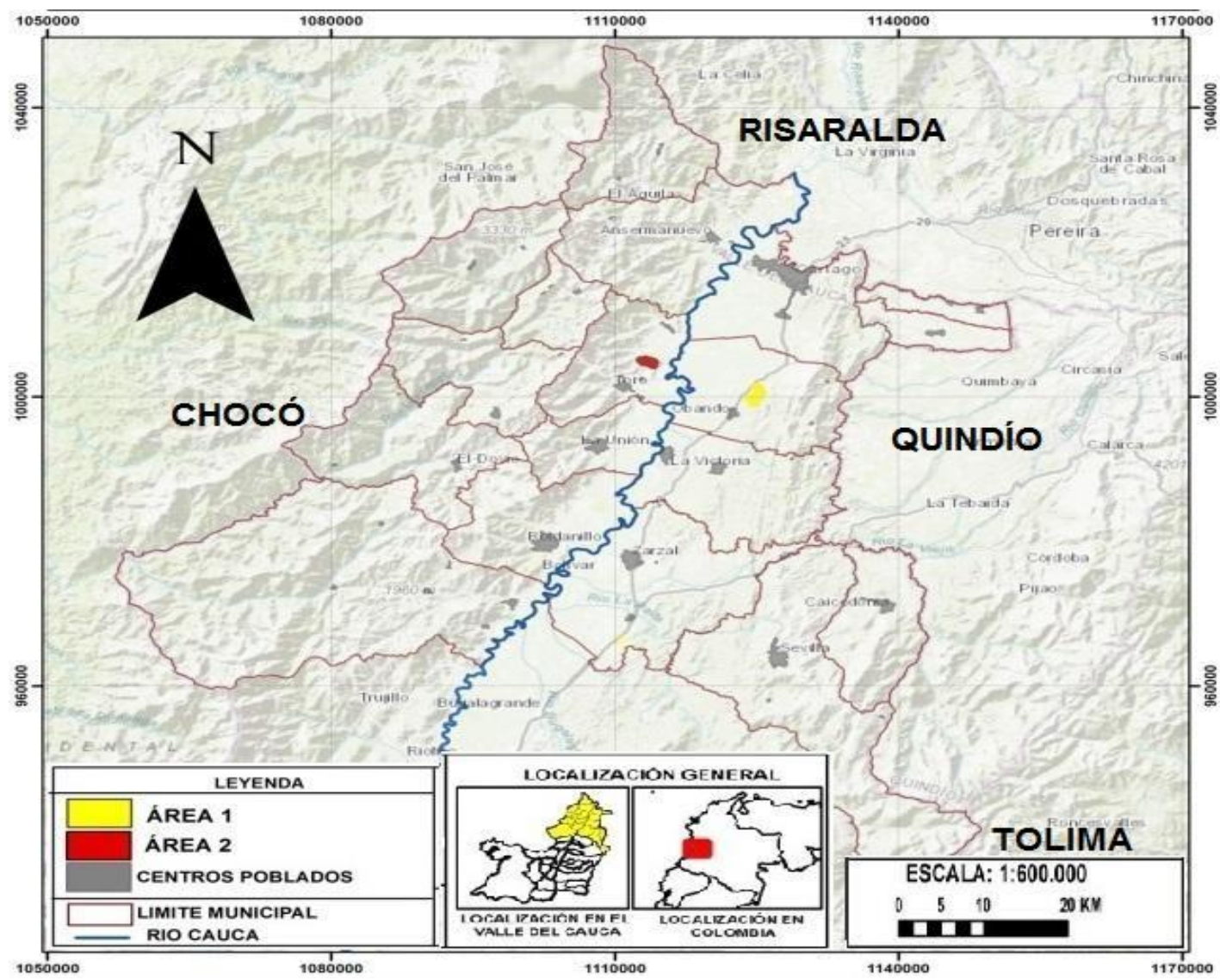

Figura 9. Localización de las áreas óptimas dentro de la zona de estudio. 


\section{Descripción de las áreas seleccionadas}

A continuación, se describe las características de cada una de las áreas seleccionadas en el estudio como posibles lugares para llevar a cabo el emplazamiento del relleno sanitario.

Área 1: El área 1 representada en la Figura 10, se encuentra localizada en el municipio de Obando, y posee una extensión aproximada de 50 hectáreas. Dentro del estudio obtuvo una puntuación general de 0.931 , lo que significa que cumple con la mayoría de los requisitos exigidos, por ende, es la más óptima.

Fuente: Google Earth (2016)

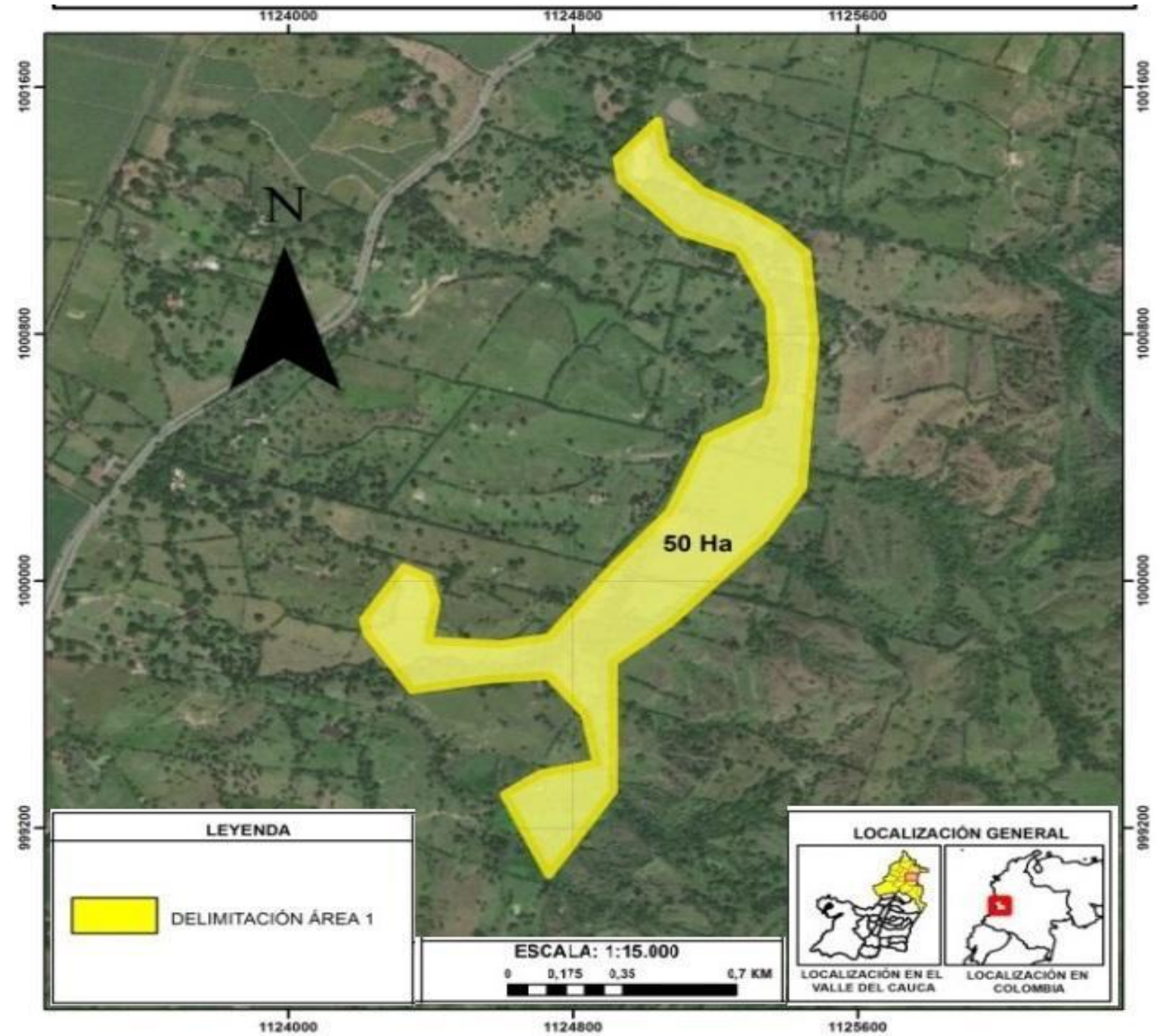

Figura 10. Localización área 1. 
Área 2: El área 2 representada en la Figura 11 , se encuentra localizada en el municipio de Toro, posee una extensión aproximada de 35 hectáreas, y dentro del estudio obtiene una puntuación de 0.834 . Por su localización central podría resultar beneficioso localizar el relleno sanitario en esta zona, sobre todo si se tiene en cuenta que se habla de un relleno subregional.

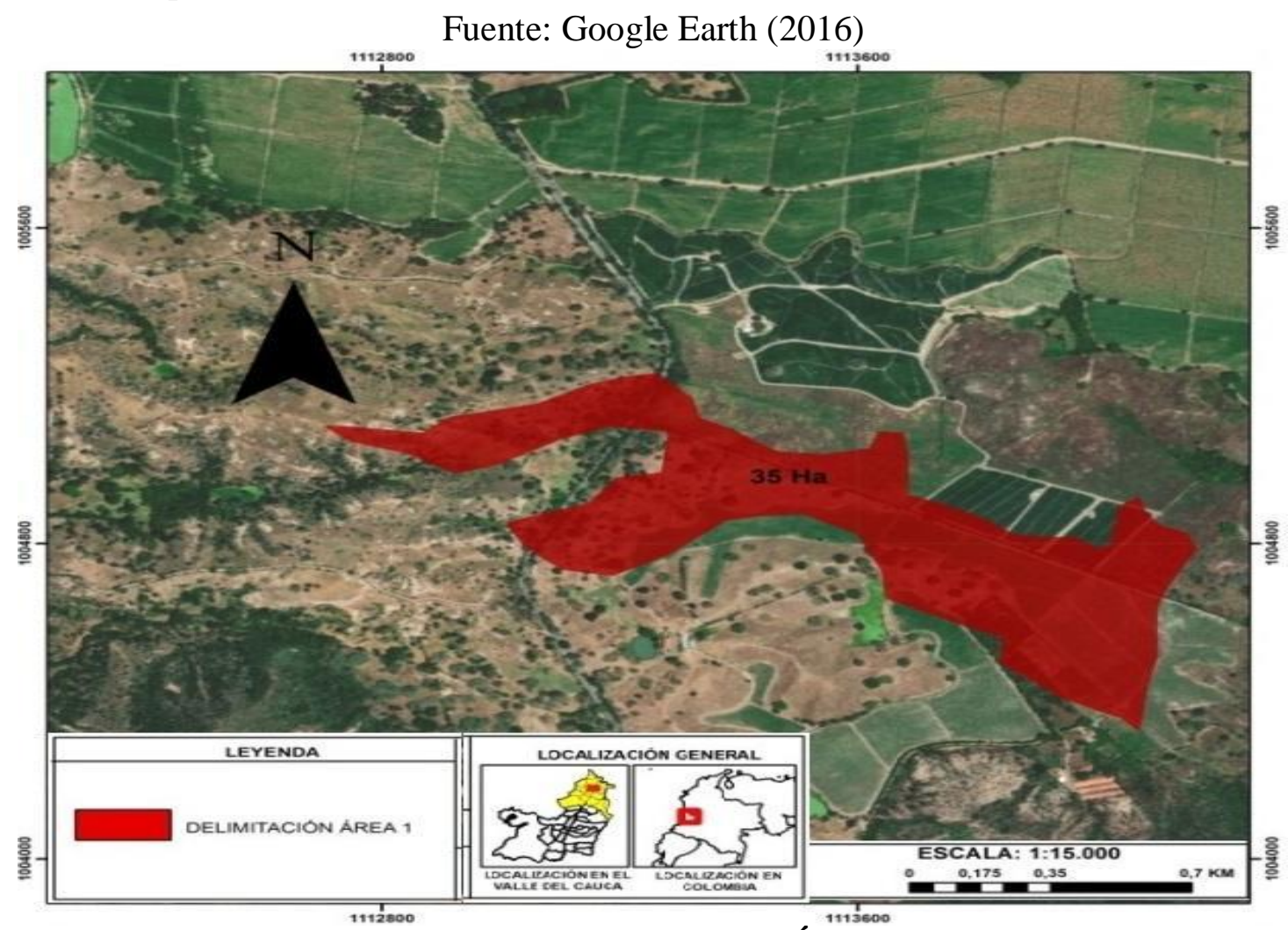

Figura 11. Localización Área 2

\section{Discusión de resultados}

Presentar una metodología para la localización de un relleno sanitario en el contexto colombiano, cuando ya está establecida una regulación al respecto, implica un aspecto fundamental, y es que la normativa no cumple con su propósito de orientar a los municipios para que puedan determinar áreas posibles donde localizar el relleno sanitario, debido principalmente, a que su metodología propuesta no es aplicable a la hora de realizar una selección previa de sitios.
El decreto 838 de 2005 busca orientar a los municipios para que por medio de su propuesta metodológica determinen áreas posibles para llevar a cabo el emplazamiento del relleno sanitario, y que posteriormente dichas áreas sean incluidas en los planes de ordenamiento territorial, sin embargo, como lo recalcan adecuadamente Valencia, Arias y Vanegas (2010) "el decreto no contempla una metodología de selección previa de sitios" (p. 66), lo que hace que su objetivo principal no se cumpla. Quizás la 
metodología que utiliza el decreto sea más práctica a la hora de efectuar la localización del relleno sanitario, pues la tabulación que se propone es adecuada utilizarla cuando ya se tienen las áreas determinadas.

Así las cosas, la metodología propuesta en este estudio cumple con los objetivos que se traza el decreto 838 de 2005, pues permite identificar áreas posibles, dentro de un determinado municipio, para llevar a cabo la localización de un relleno sanitario, y que además, tiene en cuenta la protección del espacio físico, el medio ambiente y la población, en definitiva, la metodología propuesta reconoce la heterogeneidad del territorio colombiano.

A partir de lo expuesto, la metodología propuesta se basó en el reconocimiento a las dinámicas del área de estudio, a los aportes de distintos autores que han trabajado la temática aquí tratada, al enfoque del desarrollo sostenible y a contenidos específicos del decreto 838 de 2005 en lo que a criterios de localización se refiere, esto permitió obtener resultados más confiables a partir de la selección de criterios y Subcriterios provenientes de distintos enfoques y miradas.

Cuando se realiza una evaluación multicriterio, siempre habrá aspectos que se quedan por fuera y que podrían ser determinantes, y es precisamente los riesgos que se corren al ejecutar una metodología a partir del análisis multicriterio. Es por eso que los resultados obtenidos no se pueden catalogar como definitivos y de ahí surge la necesidad de que las áreas determinadas sean evaluadas en otro proceso. Precisamente la metodología que utiliza el decreto 838 de 2005 podría ser muy útil en la evaluación de dichas áreas para determinar la más adecuada para llevar a cabo la localización final del relleno sanitario.

\section{CONCLUSIONES}

Dentro de la zona de estudio si es posible llevar a cabo la localización de un relleno sanitario, pues existen áreas que desde la parte física, social y económica son "aptas" y cumplen con la mayoría de requisitos exigidos para poder lograr el emplazamiento. Precisamente el área $1 \mathrm{y}$ el área 2 expuestas en la sección de resultados cumplen con la mayoría de requisitos determinados en cada criterio y subcriterio, sin embargo, el área 1 es las más adecuada pues es la de mayor calificación en toda la zona de estudio y su tamaño se ajusta al ideal para la localización de rellenos sanitarios regionales, el cual debe ser igual o superior a las 50 Hectáreas.

La metodología aquí propuesta permite mayor flexibilidad para determinar los procedimientos a seguir, además integra los aspectos del área de estudio, la normatividad, el enfoque del desarrollo sostenible y los antecedentes de investigación sobre la temática. Esto permite tener una visión mucho más amplia sobre la localización de los rellenos sanitarios y los procesos involucrados en la determinación de posibles áreas. 
Aunque la metodología busca ser lo más precisa posible, esta se basa en el análisis multicriterio, lo que hace que de por sí, se dejen por fuera aspectos importantes que podría ser relevantes, es decir, al basarse en múltiples criterios con pesos diferentes, se corre el riesgo de dejar de lado otros criterios, lo que hace que los resultados obtenidos no sean del todo precisos ni cien por ciento confiables, por eso surge la necesidad de someter los resultados a evaluación a través de otros procesos o metodologías.

Definitivamente la metodología contenida dentro del decreto 838 de 2005 no es aplicable para determinar áreas posibles donde localizar un relleno sanitario, sin embargo, los criterios hay expuestos si pueden ser tomados en cuenta para llevar a cabo la localización.

\section{RECOMENDACIONES}

En vista de que los municipios pertenecientes a la zona de estudio no tienen claridad en cuanto a donde llevar los residuos producidos, y por eso se presenta una dispersión de municipios llevando sus residuos a distintos lugares fuera de la zona de estudio, se hace necesario, entre otras cosas por el tamaño de la población y por la alta producción de desechos, la construcción de un relleno sanitario que facilite el proceso de gestión de los residuos sólidos municipales.
La normativa colombiana, en el decreto 838 de 2005, dicta las pautas, criterios y metodología para llevar a cabo la localización de un relleno sanitario, sin embargo, esta metodología solo es aplicable para estudiar áreas ya definidas o establecidas, pero no es aplicable cuando se trata de buscar posibles áreas de localización. Sería recomendable que se revisara el procedimiento establecido por el decreto. Esto facilita la toma de decisiones por parte de los entes territoriales a la hora de definir áreas para luego incorporarlas a los planes de ordenamiento.

En este estudio se han definido dos posibles áreas y se han expuesto algunas ventajas y desventajas para llevar a cabo la localización de un relleno sanitario, sin embargo, el proceso de emplazamiento no termina con la obtención de posibles áreas, sino que se requiere de un trabajo mucho más complejo que implica, entre otras cosas, el diálogo con la población que podría verse impactada, por eso se recomienda que a partir de este estudio, se realice un trabajo de carácter social, con el objetivo de explicarle a la población los motivos que llevaron a la elección de dichas áreas y la necesidad de construcción del relleno sanitario.

Para la localización final del relleno sanitario es necesario realizar un estudio de las áreas obtenidas a partir de la aplicación de una metodología donde la escala sea más detallada, para analizar si dichas áreas son viables. 


\section{REFERENCIAS BIBLIOGRÁFICAS}

Artaraz, M. (2002). Teoría de las tres dimensiones del desarrollo sostenible. Ecosistemas, 11(2), 16. Recuperado de https://www.revistaecosistemas.net/in dex.php/ecosistemas/article/view/614

Briñez, D. (2016). Lineamientos para el desarrollo y crecimiento del área metropolitana de Bogotá sobre la

Salud (CAPS) en la ciudad de Luján, Argentina. Cuadernos de geografía, Revista colombiana de geografía, 20(2), 111-123. doi: 10.15446/rcdg.v20n2.27184.

Cardozo C. R., y Giménez, M. (2012). Localización óptima de relleno sanitario aplicando técnicas multicriterio en Sistemas de Información geográfica (SIG) en el área metropolitana del Alto Paraná. Séptimo congreso de medio ambiente (pág. 20). La Plata, Argentina: AUGM.

Choles, V. (2013). Gestión integral de residuos sólidos en colegios sostenibles: modelos y tendencias (Trabajo de pregrado). Pontificia Universidad Javeriana, Bogotá, Colombia.

Collazos, H. (2001). Diseño y operación de rellenos sanitarios. Bogotá: ACODAL.

Gascón, S M., Jiménez, L. M., y Pérez, H. (2015). Óptima ubicación de un relleno sanitario para el área metropolitana del Valle de Aburrá empleando Sistemas de Información Geográfica. Ingenierías USBMED, 6(1), 38-45. doi: 10.21500/20275846.1722

Mena, C., Morales, Y., Ormazábal, Y., y Gajardo, J. (2010). Localización de un relleno sanitario en la comuna de Parral, Chile, a través de evaluación multicriterio. Interciencia, 35(9), 684- conexión con el nuevo aeropuerto el dorado II (Trabajo de pregrado). Pontificia Universidad Javeriana, Bogotá, Colombia.

Buzai, G. (2011). Modelos de localizaciónasignación aplicados a servicios públicos urbanos: análisis espacial de Centros de Atención Primaria de

689. Recuperado de https://www.interciencia.net/wpcontent/uploads/2018/01/684-cMENA-6.pdf.

Ministerio de Medio Ambiente y Presidencia de la República. (2005). Decreto 838. CAPÍTULO II: por el cual se establecen los procedimientos, criterios, metodología, prohibiciones y restricciones para la localización de áreas para la disposición final de residuos sólidos. Bogotá, Colombia. Recuperado http://www2.igac.gov.co/igac web/n ormograma files/Decreto\%20838\%2 0de\%202005.pdf.

Ministerio de Medio Ambiente, Vivienda y Desarrollo Territorial. (2002). Decreto 1713. Capítulo I: Definiciones. Bogotá, Colombia.

Ministerio de Medio Ambiente y Agua. (2010). Guía para la Implementación, Operación y Cierre de Rellenos Sanitarios. lera versión. La Paz, Bolivia. Recuperado de http://www.anesapa.org/wpcontent/uploads/2014/12/GuiaRell enosSanitarios.pdf.

Muñoz, B., y Romana, M. (2016). Aplicación de métodos de decisión multicriterio discretos al análisis de alternativas en estudios informativos de infraestructuras de transporte. Revista de pensamiento matemático-MAIC, 27-46. Recuperado de 
https://dialnet.unirioja.es/servlet/ar ticulo?codigo $=5998856$.

Röben, E. (2003). El Reciclaje. Oportunidades Para Reducir la Generación de los Desechos Sólidos y Reintegrar Materiales Recuperables en el Círculo Económico. Loja, Ecuador: DED (Servicio Alemán de Cooperación Social- Técnica). Recuperado de http://www.bvsde.paho.org/bvsacg/g uialcalde/3residuos/d3/062_reciclaje/ reciclaje.pdf

Rodríguez, M. (1994). El Desarrollo Sostenible: ¿Utopía o realidad?
La política ambiental del fin de siglo: Una agenda para Colombia. Bogotá: CEREC.

Valencia Londoño, D. E., Arias Muñoz, C., y Vanegas Ospino, E. (2010). Metodología para la localización de un parque de tratamiento y disposición final de residuos sólidos de tipo regional desde una perspectiva multidimensional. Revista Ingenierías, 9(17), 63-74. Recuperado de https://revistas.udem.edu.co/index.ph $\mathrm{p} /$ ingenierias/article/view/12 